\title{
Manifiesto en pro de una sociología relacional $^{1}$
}

\author{
Mustafa Emirbayer ${ }^{2}$
}

\begin{abstract}
Sociologists today are faced with a fundamental dilemma: whether to conceive of the social world as consisting primarily in substances or processes, in static "things" or dynamic, unfolding relations. Relational-actor and norm-based models, diverse holisms and structuralisms, and statistical "variable" analyses continue implicitly or explicitly to prefer the former point of view. By contrast, this "manifesto" presents an alternative, "relational" perspective, first in broad philosophical outlines, then by exploring its implications for both theory and empirical research. In the closing pages, it ponders some of the difficulties and challenges now facing relational analysis, taking up in turn issues of boundaries and entities, network dynamics, casualty, and normative implications.
\end{abstract}

En la actualidad los sociólogos enfrentan un dilema fundamental: se debe concebir el mundo social como conformado ante todo por sustancias o por procesos, por "cosas" estáticas o por relaciones dinámicas y en constante desarrollo. Un gran numero de académicos dentro de la sociología continúan implícita o

1 Nota del editor: Traducción de Alicia María Fernánde. Revisión final de Hanni Jalil Paier. Título original: "Manifest for a Relational Sociology", en: The American Journal of Sociology, Vol 103:2, 1997. pp. 281-317. Agradecemos al profesor Mustafa Emirbayer por conceder el permiso para la traducción y publicación de este artículo. Asimismo, a The American Journal of Sociology por su consentimiento. La exactitud o no de la traducción no es responsabilidad de la editorial de la Universidad de Chicago.

2 Me gustaría agradecer a Ronald Breiger, David Gibson, Jeff Goodwin, Michkle Lamont, Ann Mische, John Mohr, Jeffrey Olick, Shepley Orr, Mimi Sheller, Charles Tilly y Harrison White por sus muy beneficiosos comentarios en los primeros borradores. También me gustaría agradecer a los participantes en los seminarios en la Universidad de Princeton y en New School for Social Research (Nueva Escuela de Investigación Social) y en el Grupo de Discusión Mensual sobre Teoría y Cultura en la ciudad de Nueva York, por sus estimulantes críticas y sugerencias. Dirija su correspondencia a Mustafa Emirbayer, Department of Sociology, New School for Social Research, 65 Fifth Avenue, New York, New York 10003. 
explícitamente prefiriendo el primer punto de vista. Los modelos basados en la teoría de elección racional y los fundados en la norma, diversos holismos y estructuralismos, y el análisis de "variables" estadísticas - todos ellos apegados a la idea de que las entidades son más importantes y que las relaciones entre ellas son secundarias- predominan en gran parte de la disciplina. Sin embargo, los investigadores cada vez más buscan alternativas analíticas viables, enfoques que cambien radicalmente estas hipótesis básicas y que, por el contrario, describan la realidad social en términos dinámicos, continuos y procesales.

El propósito de este "manifiesto" es mostrar las características esenciales del anterior punto de vista. Comienza por la presentación de la perspectiva relacional en forma de esquemas amplios (por medio de una comparación con los enfoques sustancialistas a los que se enfrenta), y luego explora sus implicaciones tanto en la investigación teórica como en la empírica. En las páginas finales, también se pensará en torno a algunas de las dificultades y retos que ahora enfrenta el análisis relacional. (Todo el ensayo se enfoca en gran parte en la ontología - pero ciertamente no de forma exclusiva- haciendo a un lado preguntas relacionadas con la epistemología.) No pretendo haber sido el primero en formular cualquiera de estos temas; por el contrario, muchos sociólogos distinguidos, con un amplio rango de perspectivas teóricas y empíricas, han estado trabajando durante mucho tiempo dentro de un marco de de análisis relacional. En efecto, durante mucho tiempo este mismo marco ha sido propuesto por pensadores sociales y filósofos, podría decirse que este se remonta hasta la época de los Presocráticos. Tampoco pretendo ser exhaustivo ni en mis discusiones textuales ni en las referencias bibliográficas. "Pueden estar seguros de que, por cada idea, se podría citar un gran número de discusiones e implementaciones importantes, a menudo independientes: las ideas que tienen alguna importancia, o impacto, vienen después de todo acompañadas, y no aisladas; el ensayista es entonces más que todo un transcriptor de las ideas que se formulan fuera de sus redes" (White, 1994a: 4). Lo que he hecho aquí es solamente agrupar las diversas líneas de razonamiento en torno a esta perspectiva (filosófica, teórica y empírica); aclarar la manera en la que éstas presentan un reto importante a las premisas reinantes; por lo tanto, también trato de prevenir un tipo de eclecticismo, la mezcla fácil de los supuestos sustancialistas y relacionales, que vuelven parcialmente problemáticos muchos estudios innovadores. La pregunta clave que confronta a los sociólogos hoy en día no es "lo material versus lo ideal", "la estructura versus la agencia", 
"lo individual versus la sociedad", o ningún otro dualismo tan frecuentemente notorio; más bien, es el escoger entre sustancialismo y relacionismo. ${ }^{3}$

\section{Pensamiento sustancialista y pensamiento relacional}

La forma más adecuada para describir el punto de vista relacional con respecto a la acción social y al cambio histórico es comparándolo con en el punto de vista contrario: la perspectiva sustancialista, que toma como punto de partida la noción de que son sustancias de varias clases (cosas, seres, esencias) las que constituyen las unidades fundamentales de cualquier clase de investigación. El análisis sistemático inicia con estas entidades autosostenibles que vienen "preformadas" y sólo después se consideran los flujos dinámicos que posteriormente las involucran. "La relación no es independiente del concepto del ser real; únicamente añaden modificaciones adicionales y externas a este último, sin afectar su 'naturaleza' real" (Cassirer, 1953: 8). Un teórico social, Norbert Elias, señala que el pensamiento sustancialista está muy asociado a patrones gramaticales profundamente arraigados en lenguas occidentales. Una larga cita con respecto a estos modos de habla y de pensamiento sirve adecuadamente como introducción a esta perspectiva en términos generales:

Nuestros lenguajes se construyen de tal forma que, a menudo podemos expresar únicamente el movimiento constante o el cambio constante en forma que implica que tienen el carácter de un objeto aislado en reposo y luego, casi como una idea de último momento, se añade un verbo que expresa el hecho de que la cosa con esta característica ahora está cambiando. Por ejemplo, al estar a la orilla de un río observamos el flujo perpetuo del agua pero para entenderlo conceptualmente y comunicarlo a otros, no pensamos y decimos, "Miren el flujo perpetuo del agua"; sino que decimos: "Miren qué rápido fluye el río". Decimos: "Está soplando el viento", como si el viento fuera realmente una cosa quieta que, en determinado momento, comienza a moverse y a soplar. Hablamos como si pudiera existir una clase de viento que no soplara. Esta reducción de los procesos a condiciones estáticas, que llamaremos un "proceso-reducción" para abreviar, parece explicarse por sí mismo para las personas que han crecido dentro de estos lenguajes. (Elias 1978: 111-12)

3 Después de haber presentado estos propósitos (además con limitaciones de espacio severas), ha sido necesario suprimir otras dos clases de análisis que serían primordiales en un enfoque académico más completo: una evaluación cuidadosa y juiciosa de las alternativas sustancialistas (que tendría un desarrollo muy prometedor en la línea sustancialista de teorización, fortalezas perdurables en estos enfoques y en los demás) y una discusión sobre las diferencias internas entre los mismos pensadores relacionales: los problemas, en otras palabras, que los dividen y que los unen. En otras obras (Emirbayer y Mische, 1995; Emirbayer, 1996; Emirbayer y Sheller, 1996; Emirbayer y Goodwin, 1996, 1997), trato de desarrollar un modo específico de teoría relacional que denomino pragmatismo relacional y defender sus fortalezas con respecto a la alternativa relacional y a los enfoques sustancialistas. 
En una poco conocida pero importante discusión, John Dewey y Arthur F. Bentley (1949) distinguen entre dos variedades de enfoques sustancialistas. Al primero lo denominan perspectiva de acción auto-orientada; en el cual consideran que las "las cosas [...] actúan según sus propios poderes" (Dewey y Bentley, 1949: 108), en forma independiente de las demás sustancias. Las matrices relacionales en las que actúan las sustancias no proporcionan, según este punto de vista, mas que medios vacíos para una actividad auto-generativa y de auto-movimiento. Dewey y Bentley consideran tal perspectiva como la más característica de la filosofía antigua y medieval. "La física de Aristóteles fue un gran logro en su época pero se construyó sobre 'sustancias.' Hasta Galileo, los eruditos sostenían casi universalmente, siguiendo Aristóteles, que existen cosas que poseen el Ser en forma completa, inherente y por ende necesaria; que estas cosas continúan eternamente en acción (movimiento) bajo su propio poder -en efecto continuan, en alguna acción particular esencial en la que ellas están involucradas" (Dewey y Bentley, 1949: 110). " La doctrina cristiana del "alma", que culmina en el sistema teológico de Tomás de Aquino, tipifica este punto de vista. ${ }^{5}$ Sin embargo, después de los tiempos de Galileo, los avances en la física y en las ciencias naturales eliminaron la mayor parte de estos residuos de acción auto-orientada del estudio de la materia inorgánica.

En la filosofía moderna, sin embargo, la noción de acción auto-orientada subsiste en varias doctrinas de "la voluntad" y en la teoría política liberal (desde Hobbes, Locke y Kant), mientras dentro de las ciencias sociales mantiene un sorprendente vigor en forma del individualismo metodológico. "Todos los fantasmas, hadas, esencias y entidades que en otra época habían habitado la materia ahora huyen a nuevas casas, la mayoría en o dentro del cuerpo humano [...] la 'mente' como 'actor,' aún en uso dentro de la psicología y la sociología de esta época, es el antiguo concepto del 'alma' auto-actuante despojada de su inmortalidad" (Dewey y Bentley, 1949: 13 1). Un enfoque prevalente comienza con actores calculadores y racionales, asumiendo el hecho y la fijación de sus varios intereses, metas y "tablas de preferencia”. La teoría de la selección racional toma como cierto, como lo formula Jon Elster, que "la unidad elemental de la vida social es la acción humana individual. Para explicar las instituciones sociales y el cambio social demuestra cómo ellas surgen a partir de la acción e interacción entre individuos" (Elster, 1989: 13). Cuando los actores se involucran con otros actores cuyas circunstancias condicionan sus propias elecciones, logrando

4 Un comentarista ofrece una explicación adicional: “Según el concepto del alma de Platón, la capacidad de auto-movimiento o acción auto-orientada es la característica esencial del alma y Aristóteles nos dice en forma muy explicita en su Física de aquellas cosas que existen por naturaleza [...] 'cada una de ellas tiene en sí un principio de movimiento"” (Bernstein, 1966: 81).

5 Para Aquino, Dios Mismo fue la más perfecta substancia auto-actuante. 
resultados no buscados por ninguno de ellos de manera individual, los teóricos de la selección racional recurren entonces a la teoría de juegos. Aquí de nuevo (por lo menos en algunas de sus versiones), se considera que entidades ya predeterminadas generan la acción auto-orientada; aún en la medida en la cual los actores se involucran en los juegos con otros actores, sus intereses, identidades y otras características subyacentes permanecen inalteradas. La teoría de juegos asume que "hay dos o más jugadores. Cada uno de ellos tiene el poder de elegir entre dos o más estrategias. Cada conjunto de selecciones genera un conjunto de premios. El premio para cada jugador depende de las selecciones hechas por todos los demás, no solo de su propia decisión. Se asume que los jugadores escogen de forma independiente, en el sentido de que no pueden hacer acuerdos de carácter obligatorio para coordinar sus decisiones" (Elster, 1989: 28). Con esta sofisticación y rigor analítico, la teoría de elección racional (junto con las versiones complementarias de la teoría de juegos) rápidamente se está convirtiendo en la principal alternativa al enfoque relacional que resumiré más adelante.

Otro enfoque popular, solo en apariencias el principal rival de los modelos de selección racional, toma como unidad básica de análisis a individuos que obedecen una norma, o más específicamente, las fuerzas vitales internas que los mueven. Describe a los individuos como entidades auto-impulsantes y auto-sostenibles que buscan normas internalizadas formuladas con anticipación y fijadas durante la secuencia de acción bajo investigación. Tales individuos no aspiran a riqueza, status o poder, sino, actuar de conformidad con 'los ideales sociales que han aceptado como propios. Por lo tanto, la acción no-racional se convierte en la provincia especial de este modo de análisis, un elemento básico de la investigación sociológica. Para diferenciarse de la economía, que inicialmente respalda el enfoque del actor racional, la sociología tuvo desde un principio "la necesidad fundamental de encontrar una teoría de acción que define distintos tipos de acción con base en la diferencia especifica de la acción racional. Requería de una teoría de sociedad como un complejo de acciones interrelacionadas que va más que la interconexión imprevista de acciones en el ámbito de interés personal [...] como protección contra los peligros utilitarios de la teoría de acción racional, los teóricos fundadores de la sociología [tenían que] recurrir a Kant y a su noción de la acción libre y moral" (Joas, 1993: 246-47). Hasta hoy, la perspectiva neo-Kantiana de cumplimiento de la norma perdura en diversas formas de la teoría crítica, el análisis de valor y la microsociología.

En forma muy diferente, la idea de la acción auto-orientada también se insinúa en el pensamiento social por medio de teorías holísticas y "estructuralismos" que no plantean individuos sino "sociedades", "estructuras" o "sistemas sociales" autosuficientes como fuentes de acción exclusivas. Los proponentes de estos 
enfoques, desde los neo-funcionalistas y teóricos de sistemas, hasta muchos analistas con una perspectiva histórica y comparativa, con frecuencia recurren a la premisa de que son entidades duraderas y coherentes las que constituyen los puntos de partida legítimos de toda la investigación sociológica. Tales entidades poseen propiedades emergentes que no pueden ser reducidas a formar parte de los elementos que las componen. Son los grupos, naciones, culturas y otras sustancias cosificadas, y no personas individuales, las que llevan a cabo todos los actos en la vida social y explican su dinamismo. En algunos casos, inclusive estas secuencias de la acción puede cumplir dicha función: los movimientos sociales o luchas nacionalistas, por ejemplo, se consideran como impulsadas por trayectorias "que se repiten [...] una y otra vez en forma esencialmente igual” (Tilly, 1995a: 1596). Por lo tanto, los procesos como también las estructuras aparecen como entidades auto-actuantes en muchas instancias concretas de investigación social.

La segunda categoría clave del sustancialismo planteada por Dewey y Bentley es la de la inter-acción. ${ }^{6}$ Este enfoque, el cual se confunde frecuentemente con puntos de vista más verdaderamente relacionales, plantea "una cosa [como] balanceada con otra cosa en interconexión causal" (Dewey y Bentley, 1949: 108), donde las entidades ya no generan su propia acción, sino que por el contrario, la acción relevante ocurre entre las mismas entidades. Las entidades permanecen estaticas y sin cambios durante toda la interacción, cada una independiente de la existencia de las otras, muy parecido a las bolas de billar o a las partículas dentro de la mecánica de Newton. En efecto, fue Sir Isaac Newton quien en realidad dio a la perspectiva interaccional su expresión más exquisita. "Durante muchas generaciones, comenzando por Galileo después de su ruptura con la tradición Aristotélica y continuando mucho después de la época de Comte, el énfasis en la investigación física está en la ubicación de unidades o elementos de acción y la capacidad de determinar sus interacciones. Newton estableció con firmeza el sistema bajo el cual las partículas podían escogerse y organizarse para investigar el movimiento y así podían describirse en forma definitiva. [...] Ahora la presentación interaccional había sido perfeccionada" (Dewey y Bentley, 1949: 105, 11 1).

En la actualidad, la idea de interacción se encuentra en un punto que en forma explícita o implícita domina gran parte de la sociología contemporánea, desde la investigación mediante encuestas hasta el análisis histórico-comparativo. Este es el llamado "enfoque centrado en variables", que se caracteriza, como

$6 \mathrm{Mi}$ uso de guiones aquí sigue la misma práctica de Dewey y Bentley y hace énfasis en que uso su terminología en forma distinta a como se usa palabras como "interacción" y, como veremos, "transacción" en el lenguaje cotidiano. (A menudo, por ejemplo, interacción y transacción se usan como sinónimos, mientras que aquí representan posiciones filosóficas muy especificas -y distintas-.) Se debe tener en cuenta este punto cuidadosamente aún cuando estas palabras reaparezcan sin los guiones más adelante en el ensayo. 
señala Andrew Abbott (1988: 170), por imágenes convincentes de entidades fijas con atributos variables que "interactúan, en tiempo causal o real, para crear resultados, los mismos que son medibles como atributos de las entidades fijas. ${ }^{7}$ Lo que indudablemente no hacen las sustancias en cuestión dentro de esta perspectiva es la actuación; toda acción relevante ocurre entre ellas -por ende estas simplemente proporcionan los entornos vacíos en los que ocurre la causa- en vez de ser generados por ellas. Si acaso, son los mismos atributos variables los que "actúan", y los que aportan la iniciativa, en la investigación interaccional; "una posición desventajosa genera entonces un aumento en la competitividad", sin que exista un actor particular participando con un comportamiento competitivo. "Es cuando una variable 'hace algo' en forma narrativa que los mismos [analistas] piensan que están hablando en forma más directa de causalidad”, anota Abbott. "La metafísica realista implícita en el tratamiento de variables (universales) como agentes fue tomada en serio por última vez en la época de Aquino [...] sin embargo en este [enfoque] las 'mejores' oraciones causales son oraciones explícitamente realistas en las que actúan variables" (Abbott, 1992a: 58). Los investigadores centrados en las variables emplean una gran variedad de métodos cuantitativos para comprobar sus hipótesis causales, incluyendo regresión múltiple, análisis de factores y enfoques de eventos históricos.

Fundamentalmente opuesta a ambas variedades de sustancialismo se encuentra la perspectiva de la trans-acción, "en la que se aplican sistemas de descripción y nominalización para enfrentar aspectos y fases de la acción, sin atribuir esta en forma definitiva a 'elementos' u otras 'entidades,' 'esencias,' o 'realidades,' presumiblemente separables o independientes y sin estar aislados de 'relaciones' presumiblemente discretas de dichos 'elementos' separables" (Dewey y Bentley, 1949: 108). Según este punto de vista, que también denominaré "relacional", los mismos términos o unidades involucradas en una transacción derivan, su significado, significancia e identidad de los papeles funcionales (cambiantes) que juegan dentro de esta transacción. El último, visto como un proceso dinámico y en constante desarrollo, se convierte en la unidad primaria de análisis en vez de los elementos mismos que la constituyen. La cosas "no se asumen como existencias independientes presentes, anteriores a cualquier relación, sino que [...] obtienen todo su ser [...] primero en y con las relaciones que entre ellas se establecen. Tales 'cosas' son los términos de las relaciones y como tales no se 'dan' en forma aislada sino únicamente en una mutua comunidad ideal” (Cassirer, 1953: 36). Aunque su origen se puede remontar a los escritos de Heráclito, este modo transaccional de teorizar comienza a ser muy influyente por primera vez con el

\footnotetext{
7 En la descripción de Abbott (1988, pág. 181), el enfoque interaccional asume además "que estos atributos únicamente tienen un significado causal a la vez; [y] que este significado causal no depende de otros atributos, en la anterior secuencia de atributos, o en el contexto de otras entidades".
} 
surgimiento de nuevos enfoques en física, matemáticas y las ciencias naturales. Lo más notable es que, la teoría de la relatividad de Einstein “introdujo el espacio y el tiempo tanto en la investigación como en los eventos investigados [y] preparó el escenario para que la partícula misma fuera por el mismo camino del espacio y el tiempo. Definitivamente todos estos pasos estaban en la misma línea del enfoque transaccional: la visión en conjunto, cuando la investigación la requiera, de lo que antes se había visto separadamente y se mantenía individualmente por separado" (Dewey y Bentley, 1949: 112). ${ }^{8}$

Los teóricos relacionales rechazan la noción de que se pueden proponer unidades discretas predeterminadas tales como los individuos o la sociedad como los principales puntos de partida para el análisis sociológico (al igual que en la perspectiva de acción auto-orientada). Los individuos, estratégicos o seguidores de las normas, son inseparables de los contextos transaccionales en los que están incrustados; como lo expresa Michel Foucault, el "alma no es una sustancia; es el elemento en el que se articulan los efectos de cierto tipo de poder y la referencia de cierto tipo de conocimiento" (Foucault, 1979: 29). ${ }^{9}$ De igual modo, las estructuras son abstracciones vacías además de los varios elementos de las que están compuestos; las mismas sociedades no son sino pluralidades de individuos asociados. Los transaccionales - comenzando, de hecho, con algunos de los "fundadores" de la sociología- están casi completamente de acuerdo en este punto. Karl Marx (1978: 247) plantea, por ejemplo, que "la sociedad no consiste de individuos, sino que expresa la suma de interrelaciones, dentro de las cuales se encuentran los individuos". Cerca del final del Capital, volumen 1, observa además que el "capital no es una cosa, sino una relación social entre personas mediada por medio de cosas” (Marx, 1977: 932). Georg Simmel, el sociólogo

8 En su magistral historia de la ciencia moderna, Substance and Function (1953), Ernst Cassirer distingue entre "conceptos-relación" pertinente a este enfoque transaccional y la "conceptos-cosa" central en el pensamiento substancialista desde Platón y Aristóteles. Traza el surgimiento de la teorización relacional en una multiplicidad de áreas problema, entre las que se incluyen las teorías de espacio y numero, geometría y las ciencias naturales. En la actualidad la exploración más constante y filosóficamente sutil de la perspectiva transaccional se puede encontrar en las obras de Margaret Somers (1993, 1994, 1995; ver también Somers y Gibson 1994).

9 Los pensadores relacionales son implacables en sus críticas sobre conceptos tales como "el alma" o "la persona”. Considérese, por ejemplo, a Harrison White (1992: 197, n.21): "La persona debe ser un constructo en medio del análisis, no una condición fronteriza dada. Es necesario explicar la personeidad. [...] Sin embargo, en las ciencias sociales más actualizadas, por el contrario, 'persona' se toma como átomo indiscutido. Este es un préstamo y una transcripción no reconocida que se hace del concepto de alma a partir de la teología cristiana [...] la estabilidad final del alma, que permaneció para restringir las ciencias sociales, fue un imperativo teológico Paulino". O considere a Pierre Bourdieu (Bourdieu y Wacquant, 1992: 106- 7): "Cuando hablo de [cualquier] campo [dado], sé muy bien que en este campo encontraré 'partículas' (permítanme pretender por un momento que estamos relacionados con un campo físico) que se encuentran en el balanceo de las fuerzas de atracción, de repulsión etc., como en un campo magnético. Después de haber planteado esto, tan pronto como menciono el campo, mi atención se fija en la primacía de este sistema de relaciones objetivas sobre las partículas mismas. Además, se podría decir que, siguiendo la fórmula de un famoso físico alemán, que el individuo, como el electrón, es un Ausgeburt des Felds: él o ella es en cierto sentido una emanación del campo". 
clásico más comprometido con la teoría relacional, anota que "la sociedad es una estructura supra-singular que a pesar de todo no es abstracta. Según este concepto, la vida histórica evita la alternativa de tener que presentarse a través de una lista de individuos o como una generalidad abstracta. La sociedad es una generalidad que tiene, en forma simultánea, una vitalidad concreta" (Simmel, 1971: 69). Hasta Emile Durkheim, el "fundador" que más se identifica con las ideas substantialistas, reconoce que "la fuerza de la colectividad no es totalmente externa. [...] La sociedad puede existir únicamente en y por medio de mentes individuales" (Durkheim, 1995: 2, 11; ver Emirbayer 1996). ${ }^{10}$

$\mathrm{El}$ análisis con base en variables (al igual que la perspectiva interaccional) es una alternativa igualmente poco viable; ya que en él también se separan elementos (sustancias con atributos variables) de sus contexto espacio-temporal, analizándolos aparte de sus relaciones con otros elementos dentro de campos de determinación y cambio mutuos. Como señalan Margaret Somers y Gloria Gibson (1994: 65, 69): "Mientras una identidad social o un enfoque categórico presume que hay conceptos internamente estables, de forma tal que en condiciones normales las entidades dentro de esa categoría actuarán en forma predecible, el enfoque [relacional, transaccional] inserta al actor dentro de relaciones e historias que cambian a través del tiempo y el espacio y, por lo tanto, precluye una estabilidad categórica en la acción. [...] La clasificación de un actor como un ente divorciado de la relacionalidad analítica no es ontológicamente inteligible ni significativa" (ver también Somers, 1994; Bates y Peacock, 1989; Breiger, 1991; para un resumen de este tipo de línea de crítica, ver Wellman [1988]: 31-33). Un corolario a este punto de vista pone en duda los intentos de investigadores estadísticos de "controlar terceras variables"; ya que también estos intentos ignoran la inserción o localización ontológica de las entidades en contextos situacionales basados en una realidad. ${ }^{11}$ Aún en la medida de que los modelos estadísticos se vuelvan cada vez más complicados, aún alertas frente a los "efectos de la interacción" entre variables, estos problemas, como están arraigados en supuestos fundamentales, no desaparecen.

10 Actualmente, Niklas Luhmann (1995: 20,22) sugiere en forma similar: "No hay elementos sin conexiones de relación o relaciones sin elementos. [...] Los elementos son únicamente elementos para el sistema que los emplea como unidades y lo son únicamente por medio de este sistema”. Además, Harrison White (1992, pág. 4) recurre a la ciencia material para plantear un punto de vista similar, comparando la realidad sociocultural con una material densa y parcialmente líquida en la que ninguna entidad autosuficiente jamás se cristalizan totalmente: "No existen los átomos ordenados ni un mundo incluyente, únicamente estriaciones complejas, cintas largas reptantes como en un polímero viscoso".

11 "Nada que alguna vez ocurra en el mundo social ocurre en la 'red de otras variables.' Todos los hechos sociales están ubicados en contextos. Por lo tanto, ¿por qué tomarse el trabajo de pretender que no lo están?” (Abbott, 1992b: 6). 
Lo que distingue al enfoque transaccional es que en él se consideran las relaciones entre términos o unidades como dinámicas por naturaleza, como procesos en constante desarrollo y en curso, en vez de lazos estáticos entre sustancias inertes. "Los actores previamente constituidos entran en [transacciones] pero carecen de la habilidad para atravesar [las] pues estas son infranqueables. [Las] vadean con dificultad y muchos [de ellos] desaparecen. Lo que resulta son nuevos actores, nuevas entidades, nuevas relaciones entre viejas partes" (Abbott, 1996: 863). ${ }^{12}$ Por consiguiente, las imágenes más empleadas al hablar de transacciones son aquellas que la ven como de una actividad conjunta y compleja, en la cual no tiene sentido prever los elementos que la conforman aparte de los flujos en los que están involucrados (y viceversa). Dewey (1929: 142), por ejemplo, afirma en Experience and Nature que "la importación de [...] esencias es la consecuencia de interacciones sociales, de compañía, de ayuda mutua, de dirección y acción concertadas en la lucha, la fiesta y el trabajo". Dewey y Bentley (1949: 133), además, señalan que "nadie podría hablar con éxito del cazador y el cazado en forma aislada con respecto a la cacería. Sin embargo es igualmente absurdo organizar una cacería como un evento aislado de la conexión espacio-temporal de todos sus componentes". En Social Organization, Charles Horton Cooley (1962) suministra una analogía muy gráfica de la "creación de música en conjunto" para expresar ideas similares, ${ }^{13}$ mientras que Norbert Elias (1978: 130) invoca el "juego" para explicar su concepto clave de "figuraciones" fluidas: "Por figuración se entiende el patrón cambiante creado por los jugadores como un todo [...] la totalidad de sus actuaciones en sus relaciones mutuas". ${ }^{14}$ También aquí se podría aludir a las negociaciones o conversaciones; la idea subyacente seguiría siendo la misma - con respecto a la primacía del contexto y el proceso en el análisis sociológico. ${ }^{15}$

Para estar seguros, el punto de vista transaccional —como sus dos principales rivales substancialistas- rara vez corresponde con precisión exacta a una escuela

12 En realidad, los actores sociales, las partes en las transacciones en curso, pueden ser comunidades, firmas, o estados como pueden ser personas individuales (aunque esto último es lo que generalmente se tiene en mente). En efecto, hasta pueden ser eventos: cualquier actor, después de todo, no es sino una serie de "eventos que siguen ocurriendo de la misma manera”, eventos con "un linaje estable” (Abbott, 1996: 873, 863)

13 ““El que [una organización social], como una orquesta, produzca armonía puede ser un asunto de discusión, pero que su sonido, agradable o no, es la expresión de una cooperación vital, no puede negarse totalmente. Desde luego todo lo que digo o pienso está influenciado por lo que otros han dicho o pensado y, de una u otra forma, a su vez envía influencia propia” (Cooley, 1962: 4).

14 Zygmunt Bauman (1989) resalta la "afinidad notoria" de que esta imagen de figuraciones parecidas al juego apoyan la "teoría de la estructuración” de Anthony Giddens. Aquí "el jugar" claramente significa algo muy diferente, por supuesto, a las auto-acciones de la teoría de juegos (aunque veáse el siguiente párrafo).

15 La naturaleza primordialmente agencial de las analogías antes mencionadas, su énfasis en la transformación como también en la iteración, puede notarse; lo que suscita muchas preguntas, raramente enfrentadas, con respecto a las dimensiones normativas de la acción social. Reanudaré estos temas a continuación. 
de pensamiento en particular o al trabajo de un individuo; lo que a menudo es de gran interés, en efecto, es exactamente la forma en que esos enfoques típicos ideales, por una parte, y los autores, textos, o investigación de tradiciones reales, por otra parte, se entrecruzan: cómo, por ejemplo, un pensador va y vuelve (a menudo implícitamente) entre varios puntos de vista. ${ }^{16}$ Esto es evidente tanto en el caso de los pensadores clásicos como de los contemporáneos. Marx, por ejemplo (como se sugiere en sus citas anteriores), fue un pensador profundamente relacional; esto queda claro desde su primer análisis de alienación (Ollman, 1971), su discusión del fetichismo de productos, sus ideas inteligentes sobre las relaciones internas entre producción, distribución, intercambio y consumo y, en efecto, su comprensión de la relación capital-salario-labor. ${ }^{17}$ Sin embargo, aún Marx exhibe tendencias sustancialistas, ante todo en su reificación de los intereses de clase, en su suposición de que los actores dentro de la misma categoría de clase (al grado de que son una "clase en sí misma") actuarán de forma similar aún si están situados en forma diferenciada dentro de los flujos de transacciones o "entorno relacional" (Somers, 1994). Entretanto, y de la dirección opuesta, el ahora teórico clásico, Talcott Parsons exhibe tendencias aparentemente en línea con el sustancialismo. Su teoría de acción se orienta complemente en la dirección del razonamiento de la acción auto-orientada, con base en la norma, mientras que sus ideas sobre el orden sugieren a menudo el holismo y la cosificación de metas del sistema. Sin embargo, aún Parsons, especialmente después del desarrollo de su último "modelo de intercambio" y su teoría de "los medios generalizados" (Parsons, 1953, 1969), se mueve con firmeza en la dirección de un punto de vista relacional y transaccional. ${ }^{18}$ Finalmente, entre los teóricos contemporáneos y las tradiciones de la investigación, la teoría de juegos es emblemática de los modelos de actores racionales (por ejemplo, de acción auto-orientada), como se mencionó anteriormente, y sin embargo, también ella, a menudo exhibe temas claramente transaccionales, como en los estudios de juegos repetidos en los que actores insertados temporalmente participan en secuencias de acción contingente mutua (ver Kreps, 1990; Macy, 1991).

16 Tal vez el teórico que comprendió con más firmeza la distinción entre lo analítico y lo concreto fue Talcott Parsons (1937). "Nunca [...] aseguró Parsons que las teorías que en realidad existieron históricamente son idénticas a las distintas posiciones lógicas que él resumió. En efecto, la mayoría de ellas son versiones opacas o combinaciones de varias de estas alternativas lógicas" (Joas, 1996: 12).

17 "Dentro de un punto de vista relacional [tal como el de Marx], la clase trabajadora se define por su ubicación cualitativa en una relación social que define en forma simultánea la clase capitalista. [...]Las clases como fuerzas sociales son consecuencias reales de las relaciones sociales" (Wright, 1979: 6-7).

18 Como señala Jeffrey Alexander, se vuelve muy revelador el hecho de que dichas tendencias discordantes entre los teóricos clásicos - por ejemplo, Marx y Parsons- posteriormente se manifiestan en las obras de sus seguidores: "Los miembros de un escuela sociológica cambian el pensamiento del fundador tanto como fielmente lo articulan y [...] lo cambian, aún más, de manera que pueda relacionarse en forma sistemática con las tensiones analíticas en la posición teórica original" (Alexander, 1983,: 277). 
A pesar de estos ejemplos concretos, todavía es válido afirmar que el sustancialismo (tanto en su forma misma como en su forma de interaccionar) y el relacionalismo (o transaccionalismo) representan puntos de vista fundamentalmente diferentes sobre la naturaleza misma y la constitución de la realidad social.

\section{Implicaciones teóricas}

Las implicaciones del enfoque transaccional son de gran alcance. A continuación, especificaré esas implicaciones desde dos puntos de vista diferentes: los de conceptos sociológicos claves y los de niveles de investigación -que van desde una vision "macro" a una vision "micro".

Para comenzar, los conceptos centrales en el análisis sociológico - por ejemplo, poder, igualdad, libertad y agencia (para mencionar varios de los citados) - están abiertos a una amplia reformulación a partir del pensamiento relacional. Tómese el concepto clave de poder, que generalmente se considera en términos sustancialistas como una entidad o una posesión, como algo que se puede "agarrar" o "tener". ${ }^{19}$ En el enfoque transaccional, "el concepto de poder [se] transforma de un concepto de sustancia a un concepto de relación. En el núcleo de las figuraciones cambiantes - en efecto, el centro mismo del proceso de figuración - es un equilibrio fluctuante, tenso, un balance de poder moviéndose de un lado a otro. [...] Esta clase de balance de poder fluctuante es una característica estructural del flujo de cada figuración" (Elias, 1978: 131). Los analistas contemporáneos de las redes sociales definen poder en términos relacionales similares, como una consecuencia de las posiciones que los actores sociales ocupan en una o más redes (Knoke, 1990). También lo hacen teóricos como Michel Foucault y Pierre Bourdieu. Las "relaciones de poder", según Foucault, "no están en una posición de exterioridad con respecto a otros tipos de relaciones (procesos económicos, relaciones de conocimientos, relaciones sexuales), sino que emanen de las últimas; son el efecto inmediato de las divisiones, desigualdades y desequilibrios que ocurren en estas últimas y son además las condiciones internas de estas diferenciaciones" (Foucault 1990, pág. 94). Bourdieu también defiende un punto de vista relacional: "Por campo

19 Esta conceptualización es aún popular a un grado tal que la interpretación de poder de Weber conserva (explicita o implícitamente) su influencia en la sociología política. "Max Weber proviene del modelo de acción teleológico [es decir, de acción auto-orientada] en el que un individuo o un grupo tiene un propósito definido y escoge los medios adecuados para llevarlo a cabo. El éxito de la acción consiste en lograr una condición en el mundo que logre el propósito determinado. El grado en que este éxito dependa de la conducta de otro sujeto, el agente tiene que disponer de los medios que instiguen la conducta deseado por parte del otro. Max Weber llama poder a este poder manipulativo sobre los medios que ejercen influencia sobre la voluntad del otro" (Habermas 1983, pág. 173). 
de poder quiero decir las relaciones de fuerza que resultan entre las posiciones sociales para garantizar a sus ocupantes un quantum de fuerza social, o de capital, de modo tal que ellas logren participar en la lucha por el monopolio del poder" (Bourdieu y Wacquant 1992, págs. 220-30). Lejos de ser un atributo o propiedad de los actores, entonces, el poder no puede pensarse por fuera de matrices de las relaciones de fuerza; ya que surge de la misma forma en que las figuraciones de relaciones se estructuran y operan y que son como veremos, de naturaleza cultural, estructural-social y psicológica-social.

La idea de igualdad también se puede reformular en términos transaccionales. Generalmente, la igualdad (como la desigualdad) se define esencialmente como un asunto de variaciones individuales en la posesión de "capital humano" o de otros bienes. ${ }^{20}$ Las causas primordiales de igualdad (y desigualdad), además, están ubicadas en las tendencias y acciones de las entidades tales como grupos o individuos, en lugar de las relaciones en constante desarrollo entre ellas: en actitudes tales como racismo, sexismo y chauvinismo étnico. Sin embargo, en las palabras de Charles Tilly (1995b: 48): "los vínculos, no las esencias, aportan las bases de desigualdad duradera". La desigualdad proviene en gran parte de las soluciones que los actores de las élites y los que no pertenecen a las élites improvisan frente a problemas organizacionales recurrentes - retos centrados en torno al control sobre recursos simbólicos, de posición o recursos emocionales. Estas soluciones, que involucran la implementación de distinciones categóricas injustas, parecen como "movidas" en un juego o tal vez como intentos de cambiar las reglas del mismo. Los miembros de una red determinada por categorías, por ejemplo inmigrantes recién llegados, adquieren control sobre un recurso valioso (por ejemplo, información sobre oportunidades de empleo), acaparan el acceso a este (por ejemplo compartiendo únicamente con otros en sus redes personales) y desarrollan prácticas que perpetúan este acceso restringido (por ejemplo, permaneciendo en contacto con sus lugares de origen por medio de correspondencia y visitas al hogar con frecuencia). Diferencias fuertes y duraderas frente a las ventajas y desventajas se cristalizan luego en torno a dichas prácticas. Por lo tanto, las transacciones en desarrollo y no los atributos preconstituidos son las que explican con más efectividad conceptos como la igualdad y la desigualdad.

Tercero, la noción de libertad también está abierta a una reformulación de gran alcance en términos relacionales. Una forma de pensar muy comúnmente sobre

20 "Enfrentados a las diferencias en salario entre hombres y mujeres, los investigadores buscan diferencias promedio en el capital humano entre los individuos involucrados. Puesto que se encuentran diferencias en la asignación de tareas, los investigadores preguntan si en todas las categorías hay diferencia en la distribución de los individuos con respecto a la ubicación de su residencia. El descubrir evidencias fuertes de diferencias étnicas en la concentración industrial, los analistas únicamente comienzan a hablar de discriminación cuando han eliminado diferencias individuales en educación, experiencia laboral o productividad" (Tilly 1995b, pág. 9). 
la libertad (u opciones) en términos sustancialista, piensa en esta como posesión, un "status legal representado por medio de leyes" (Stinchcombe, 1995: 126) y la contrasta con el status igualmente esencialista de la esclavitud. Sin embargo, como indica Arthur Stinchcombe (1995: 126), la libertad se describe mejor en forma pragmática como un conjunto de "libertades [...] cuando de hecho se goza [de ellas], sea que sean defendidas por la ley o no". Recurriendo a John R. Commons (1924: 19), quien advirtió que las ideas tales como la libertad se refieren no a una "cosa en sí, sino [a] los 'usos' esperados de la cosa, esto es, [a] diversas actividades con respecto a la cosa", Stinchcombe (1995: 126) considera la libertad no como un atributo fijo y predeterminado sino más bien a lo que podemos hacer bajo unas circunstancias determinadas: "Una opción crea una exposición de los otros a las distintas consecuencias de diferentes toma de decisiones por parte de la persona libre. [...] Por lo tanto, la definición de esta es una suma de opciones disponibles en la práctica, incluyendo en particular la capacidad social de lograr que otros sufran las consecuencias de [nuestra] [...] libertad [...] o práctica para decidir". Libertad, en otras palabras, no significa nada distinto de las transacciones concretas en las que participan los individuos, en contextos de acción culturales, estructurales- sociales y psicológico-sociales específicos; su significado proviene totalmente de la interacción en curso (semejante a un juego) entre decisión, consecuencia y reacción. "Yo [...] sostengo", afirma Stinchcombe, "que este aporte hacia la comprensión de las variaciones de libertad nos ayuda a salir de las limitaciones de definir en la definición de libertad, o esclavitud, por su esencia. Ya que definir las cosas por sus esencias siempre es algo complicado en una ciencia explicativa" (Stinchcombe, 1995: 130). ${ }^{21}$

Finalmente y en relación a esto, la idea de agencia también se puede reconceptualizar desde una perspectiva transaccional. (Por supuesto, este ejercicio en reconceptualization podría extenderse también a otros términos claves en el léxico sociológico.) Agencia se identifica comúnmente con la noción de acción auto-orientada en la "voluntad humana", como una propiedad o principio vital que "le da vida" a sustancias pasivas, inertes (individuales o grupos) que de otra forma habrían permanecido perpetuamente inmóviles. Por contraste, dentro del punto de vista relacional se considera la agencia como inseparable

21 Una concepción similar de libertad se puede encontrar en la obra de Simmel, especialmente en The Philosophy of Money (1990) y Soziologie (1950):"[La categoría de libertad] implica no una mera ausencia de relaciones sino más bien una relación muy específica hacia otros" (Simme1, 1990: 298; citado en Breiger, 1990: 457)".La libertad en si misma es una relación específica con el medio ambiente. [...] No es ni un estado que existe siempre y que se puede tomar por sentado, ni la posesión de una sustancia material, por decirlo de algún modo, que se ha adquirido de una buena vez. [...] [Esta] no es una existencia solipsistica sino una acción sociológica. [...] Esto lo sugiere el simple reconocimiento del hecho que el hombre no únicamente quiere ser libre sino que quiere usar su libertad con algún propósito" (Simmel, 1950: 120-21.) Para un debate de Simmel sobre la libertad, ver Breiger (1990). 
de la dinámica en el desenvolvimiento de situaciones, especialmente de las problemáticas características de esas situaciones. Como se concibe en otros lugares (Emirbayer y Mische, 1998), agencia conlleva a "la participación de actores de ambientes estructurales diferentes [que] reproducen y que también transforman esas estructuras como una respuesta interactiva a los problemas planteados por situaciones históricas de cambio". ${ }^{22}$ Vista internamente, la agencia involucra entonces distintas formas de experimentar el mundo, aunque aún aquí, así como la conciencia siempre es la conciencia de algo (James, 1976; Husserl, 1960), también así la agencia siempre es "la agencia hacia algo", por medio de lo cual los actores pueden entrar en una relación con personas, lugares, significados y eventos que los rodean. Visto desde afuera, conlleva transacciones concretas en contextos relacionales (culturales, estructurales sociales y psicológicos sociales) en algo muy parecido a una conversación en curso. La agencia siempre es un proceso dialógico por medio del cual los actores inmersos en la duración de la experiencia vivida se involucran con otros en contextos de acción organizados colectivamente, en lo temporal como también en lo espacial. La agencia depende del camino y también se inserta en una situación; le da significado a las modalidades de respuesta a problemas que la afectan, a veces a lo largo de amplias extensiones de tiempo y de espacio.

Además de estos conceptos generales, el punto de vista transaccional permite la reconceptualization de niveles de investigación bien diferenciados, y sui generis, en un continuo desde una visión "macro" a una visión "micro". ${ }^{23} \mathrm{En}$ el nivel más macroscópico, por ejemplo, a menudo sociedad se interpreta y define como un "sistema" autónomo, internamente organizado, auto sostenible. A menudo, pensadores dentro de la sociología asumen que la investigación debería comenzar con entidades naturalmente delimitadas, integradas y soberanas como lo son los estados, las naciones o los países. En efecto, este enfoque no es del todo inverosímil, pues no solamente el sistema estatal europeo ha estado en ascenso durante dos siglos o más sino que también, durante gran parte de la historia universal, redes dispares de interacción, en el ámbito económico, militar, político y demás, con frecuencia han convergido (o se han "institucionalizado" (Mann, 1986)) en sociedades coherentes pero bien diferenciadas. Sin embargo, los límites entre estados nacionales se superponen en forma dispar en cuanto a poblaciones, territorios, producción y patrones de consumo, identidades

22 ‘Esta concepción se parece mucho al pensamiento pragmático clásico: “El sujeto es quien sufre, es sometido y soporta resistencia y frustración; también es quien intenta superar condiciones hostiles; quien toma la iniciativa inmediata al reconstruir la situación como es" (Dewey, citado en Colapietro 1990: 653). Discutiré esta conexión teórica al pragmatismo con más detalle más adelante.

23 Para una discusión sobre niveles analíticos similares (pero no idénticos) sobre lo que sigue, ver la distinción cuádruple que plantea Wiley (1995,capítulo. 61 entre niveles: propio, interaccional, social-organizacional y cultural). 
culturales, compromisos emocionales colectivos, etc., mientras que las "interacciones de los intersticios", tanto en los estados como a lo largo de todas las unidades delimitadas, frecuentemente también revelan visiones de éstas como entidades desproblematizadas y unitarias: "Las sociedades nunca han sido lo suficientemente institucionalizadas para prevenir el surgimiento de los intersticios. Los seres humanos no crean sociedades unitarias sino una diversidad de redes de interacción social con mutua intersección. Las más importantes de estas redes se forman de manera relativamente estable. [...] Pero por debajo, los seres humanos están empujando para lograr sus metas, formando nuevas redes, extendiendo las viejas redes y manifestándose más claramente con configuraciones rivales" (Mann, 1986: 16). Como ha planteado Michael Mann (1986: 1), las "sociedades" se ven mejor "conformadas por múltiples redes de poder socioespaciales que se sobreponen e intersectan". ${ }^{24}$ Somers (1994: 72) va aún más allá al reemplazar el término "sociedad" por el de "escenario relacional", que define como "una matriz con patrones, que tiene relaciones institucionales entre prácticas culturales, económicas, sociales y políticas. ${ }^{25}$ Una conclusión como ésta no invalida el estudio histórico-comparativo del estado-nacion o "países" (ver Goodwin, 1995), pero sí recomienda gran precaución al asumir su primacía como unidades de análisis sociológico.

También en el "nivel-medio", la perspectiva relacional conduce a reconceptualizaciones significativas. En la medida en que han sido teorizados, los encuentros cara a cara generalmente se consideraban (por lo menos antes de Erving Goffman) en términos de la acción auto-orientada, como una cuestión de interacción mutua entre actores preconstituidos y autosuficientes. Goffman precisamente destruye este marco en sus reconocidos estudios sobre "copresencia” y el "orden de interacción". De primordial importancia para "el estudio apropiado de la interacción [cara a cara]", sostiene Goffman, "no es el individuo y su psicología, sino más bien las relaciones sintácticas entre los actos de diferentes personas mutuamente presentes" (Goffman, 1967: 2). Se requiere de una "sociología de ocasiones" que tome como su unidad de análisis un proceso parecido al juego, que se desdoble y sea dinámico, un proceso que se desarrolla en matrices culturales, estructurales sociales y psicológicas sociales. (En lo que podría servir como epígrafe de todo este manifiesto, Goffman [1967:

24 En la siguiente sección enfocaré varios de estos contextos de red.

25 “"Para la mayor parte de quienes practican la investigación en ciencias sociales, una sociedad es una entidad social. Como entidad, tiene una esencia núcleo - un conjunto esencial de resortes sociales en el corazón del mecanismo. A su vez, este núcleo esencial se refleja en instituciones sociales covariantes más amplias incluidas en el sistema. [...] [Por contraste,] el aspecto más significativo de un escenario relacional es que no hay ninguna entidad dominante según la cual todo el entorno se puede categorizar; se puede caracterizar únicamente descifrando sus patrones espaciales y de red y los procesos temporales. Como tal, es una matriz relacional, similar a una red social” (Somers, 1994, págs. 70, 72; ver también: Somers, 1993; Somers y Gibson, 1994). 
31] afirma: "Entonces, no son los hombres y sus momentos, sino más bien los momentos y sus hombres"). ${ }^{26}$ Por lo tanto, el estudio de los encuentros cara a cara se convierte en un asunto de localizar regularidades en todos estos procesos transaccionales, de especificar mecanismos recurrentes, patrones y secuencias en "ocasiones" del nivel-medio.

Al nivel microscópico de análisis, igualmente, la noción de individuo también se puede reprocesar de forma significativa desde un punto de vista relacional. Las identidades e intereses individuales no están preconstituidos ni desproblematizados; las partes en una transacción no entran en relaciones mutuas con atributos ya dados. Al reinterpretar la idea de Hobbes sobre el "estado de la naturaleza”, Alessandro Pizzorno (1991) demuestra cómo dichos argumentos son internamente contradictorios; se consideran como entidades autosuficientes lo que de hecho son actores, para comenzar, carentes de identidades estables y duraderas. Las identidades, para no mencionar los intereses que les corresponden, requieren de una confianza mutua y un reconocimiento recíproco para llegar a ser, condiciones que por casualidad están ausentes en el estado de la naturaleza, en el que prevalece una "guerra de cada uno contra todos". "Los individuos amenazados por la naturaleza y la inestabilidad" logran "la conservación de si mismos, la formación del yo real" (Pizzorno, 1991: 220, 2 18) únicamente por medio de procesos transaccionales de reconocimiento y lo que Pizzorno denomina "asignación de nombres": "La ficción de los individuos que aún no están involucrados en relaciones sociales pero que originalmente saben cuáles son sus intereses y cuáles podrían ser las consecuencias de sus elecciones se descarta en favor de un punto de vista en el que la interacción entre personas que reconocen mutuamente su derecho a existir es la única realidad originalmente concebible. No se imaginan intereses preestablecidos. El agente individual se constituye como tal cuando otros individuos lo reconocen y le dan un nombre" (Pizzorno, 1991: 220). Por consiguiente, las identidades individuales se constituyen dentro de "círculos de reconocimiento", mientras que los intereses (un constructo secundario) "surge de las distintas posiciones en las [estas] redes y círculos" (Pizzorno, 1991: 219). ${ }^{27}$ Tales círculos de reconocimiento pueden incluir círculos

26 Goffman (1967, pág. 2) caracteriza estos momentos como "entidad[es] cambiante(s), necesariamente evanescentes, creadas por llegadas y muertas por las salidas". Como lo explica mejor Arthur Stinchcombe (1991, pág. 373): "Las mismas personas actúan en forma diferente si están dentro de las fronteras temporales y espaciales y comunicativas de [dicha (s)] situación[es] que si están fuera de estas fronteras”. Ver también White (1973).

27 Vea en Melucci (1996) una discusión sobre las dimensiones relacionales de la identidad colectiva que desarrolla (aunque implícitamente) por medio de una línea parecida a la de Pizzorno. En forma realmente transaccionalista, Melucci hace énfasis en la naturaleza fluida y procesal de la identificación colectiva, un punto de vista, sin embargo, que no encaja fácilmente con su propia terminología substancialista, como él mismo reconoce: "Deberíamos [...] notar el hecho de que el término 'identidad' permanece semánticamente inseparable de la idea de permanencia y podría, tal vez por esta misma razón, no ser el indicado para el análisis procesal que estoy defendiendo" (Melucci, 1996: 72). 
"virtuales" con ideales culturales y objetos imaginados, como también círculos de relaciones interpersonales y sociales. Las teorías feministas contemporáneas han desarrollado conceptos muy similares; en efecto, los estudios de género en general, podrían ser el enfoque que en las ultimas décadas ha divulgado más ampliamente los modos de razonamiento transaccionales en las ciencias sociales. Ver, por ejemplo, Scott (1988); Benhabib (1992); ver también la obra importante de Somers sobre "identidad narrativa" (es decir, Somers y Gibson, 1994).

Al profundizar aún más a nivel individual, las perspectivas relacionales también hacen posible el cambio de actores en líneas teóricas de reconocido prestigio con respecto a los procesos intrapsíquicos. En la literatura psicoanalítica, por ejemplo, el punto de vista estándar es aquel de la teoría de los impulsos (drive theory), que conceptualiza al actor individual como una entidad separada, monádica, con necesidades basadas en lo físico y que busca una expresión psíquica en forma de deseos sexuales y/o agresivos. Estos deseos, que están preconstituidos, entran en conflicto con las exigencias tanto de la civilización humana como del mundo natural; la vida psíquica se construye en torno a "compromisos" entre ellos y las defensas que los controlan y canalizan. Por contraste, una nueva escuela de pensamiento en el psicoanálisis categóricamente rechaza esta perspectiva esencialista y propone una teoría de "individualismo relacional", que examina las transacciones con otros y no los impulsos predeterminados, como unidades básicas para la investigación psicológica. "La teoría entre objeto-relaciones no necesita idealizar un hiperindividualismo sino que asume una relación interna fundamental y una relación externa con el otro. Entonces, la pregunta es qué clase de relación esta debería ser. El individuo relacional no se reconstruye en términos de impulsos o defensas de él o de ella sino en términos de la mayor o menor fragmentación del mundo interno de él o de ella y el grado al cual la identidad núcleo se percibe como espontánea y se íntegra internamente y no impulsada por este mundo" (Chodorow, 1989a: 159). ${ }^{28}$ Los teóricos freudianos

28 Estas mismas hipótesis son cruciales para la nueva "escuela relacional” en la teoría psicoanalítica. En este enfoque, como lo resume Stephen Mitchell (1988:3), "Se nos describe [como] conformados por e inevitablemente insertos en una matriz de relaciones con otras personas. [...]. El deseo siempre se experimenta en el contexto de la relación y es ese contexto el que define su significado. La mente se compone de configuraciones relacionales. Únicamente se puede comprender a la persona dentro de su tapiz de relaciones, pasadas y presentes". 
de género (por ejemplo, Chodorow, 1978, 1989b; Benjamin, 1988) utilizan tales conceptos con gran eficacia. ${ }^{29}$

\section{Direcciones y técnicas de investigación}

Además de tener implicaciones de gran alcance en la investigación teórica, la perspectiva transaccional también propone nuevas y apasionantes direcciones para la investigación substantiva. En esta sección, se considerarán varias de estas líneas de investigación más empíricas, usando como principio organizador la idea de tres contextos transpersonales y relacionales a partir de los cuales se desarrollan todas las acciones sociales: estructura social, cultura y psicología social. Presumo que cada uno de estos "ambientes" (Alexander, 1988) opera de acuerdo con su propia lógica parcialmente autónoma, intersectando con los otros de formas variadas e interesantes que requieren del estudio empírico (para una discusión más completa, ver Emirbayer y Goodwin (1996, 19971; Emirbayer y Sheller [1996]). También discutiré nuevas investigaciones a nivel del individuo las cuales también se desarrollan a partir de supuestos transaccionales. ${ }^{30}$

Los enfoques mejor desarrollados y más usados en el análisis de la estructura social son claramente los de análisis redes sociales. Esta perspectiva no es fundamentalmente una teoría, ni tampoco un conjunto de complicadas técnicas de investigación, sino más bien una nueva familia muy completa de estrategias analíticas, un paradigma para el estudio de como recursos, bienes o incluso posiciones, fluyen entre figuraciones particulares de lazos sociales. Al evitar enfoques de acción auto-orientada que comienzan con individuos o grupos preconstituidos, como también enfoques interaccionales tal como los análisis estadísticos (de variables), los analistas de redes llevan a cabo estudios transaccionales de relaciones sociales con base en patrones (Breiger, 1974). Ellos se adhieren a lo que se ha denominado como un "imperativo anti-categórico" (Emirbayer y Goodwin, 1994), rechazando la primacía de las categorías atribuyentes y de otras categorías substantivas en pro de la dinámica establecida por "relaciones-en-proceso observables" (White, 1997: 60) —nótese aquí la

29 El pensamiento transaccional también aparece en las teorías no psicoanalíticas. Por ejemplo, Norbert Wiley combate tanto las antiguas como las nuevas versiones de la psicología de las aptitudes que proponen propiedades predeterminadas e innatas en la naturaleza humana, en favor de una perspectiva más "dialógica” por influencia de C. S. Peirce y George Herbert Mead. Para él, el yo es una estructura que consiste de tres elementos: la identidad, el tú y el mi, en interacción continúa el uno con el otro y con las otras identidades en un "flujo semiótico" continúo de significado. Desde la perspectiva transaccional de Wiley (1994: 72) , la identidad es "una especie de plaza pública [...] cuyos miembros están en conversación constante”. Aquí también es relevante señalar las obras de Kenneth Gergen (por ejemplo, 1994).

30 Aunque cubriré ampliamente muchas y diversas literaturas empíricas, deseo subrayar aquí la conveniencia de que finalmente se elabore un lenguaje común relacional dentro del cual se teorice sobre todos estos diversos contextos y niveles de análisis. 
combinación exitosa de imágenes temporales y espaciales- por medio de las cuales pasan el dinero, la amistad, la información y otros elementos. ${ }^{31}$ (Esto no significa que en ciertos casos los analistas de redes no dan más privilegio a la sincronía que a la diacronía, a las figuraciones espaciales que a las temporales, un punto al que regresaré más adelante. Tampoco significa que nunca importen en sus explicaciones basadas en supuestos auto o interacciónales, más problemático aún es el enfoque de selección racional con respecto a la acción; para una crítica de dicho eclecticismo, que también ocurre en otras líneas de investigación transaccional, (véase Emirbayer y Goodwin, 1994). Aquí lo importante es la noción de que las redes sociales atraviesan comunidades discretas y otras entidades -son "intersticiales" - aunque en ciertos casos también podrían solidificarse en grupos y conjuntos delimitados (los investigadores de redes hablan en tales instancias de, por su sigla en inglés, de "CATNETS") (CATegorías + REDes; ver White, 1966; Tilly, 19781). Es también importante entender que las transacciones que se desarrollan en las redes sociales no siempre son simétricas por naturaleza: a menudo los flujos son "direccionales" en contenido e intensidad, con implicaciones significativas para el acceso diferencial de los actores a los recursos. Finalmente, con frecuencia es importante la formación de patrones relacionales invisibles entre actores - "relaciones visibles únicamente por su ausencia" (Burt, 1992: 181) - puesto que dichos "agujeros estructurales" o brechas en las redes generalmente denotan disparidades en el acceso tanto a la información como a los beneficios de control.

Los analistas de redes utilizan mucho las metodologías de la sociometría y de la teoría de gráficos (el estudio matemático de los patrones estructurales en los puntos y líneas) para representar formalmente las figuraciones sociales. También recurren a las técnicas de "escalamiento multidimensional" para ilustrar a veces patrones complejos en tales vínculos y la teoría de conjuntos para modelar estructuras de roles en forma algebraica (ver un resumen de ello

31 Peter Bearman proporciona una ilustración vívida de la utilidad comparativa de los enfoques de análisis de redes y los análisis de categorías para comprender la acción social de las élites en Inglaterra desde 1540 a 1640: "Considérese el tortuoso debate sobre las bases apropiadas para clasificar la alta burguesía, puesto que los historiadores llegaron a reconocer que la alta burguesía, como grupo, no actuaba ni coherente ni uniformemente en materia de intereses. Una solución primaria al problema ha sido una continua subcategorización y ahora tenemos como grupos principales el intermedio, el oficial, el en ascenso, el en descenso, el de la corte y el del campo, para nombrar únicamente los más sobresalientes. Estas subcategorías sí corresponden a los atributos de la alta burguesía real. [...] Sin embargo, había la misma posibilidad de que la alta burguesía de la corte surgiera o declinara; que la Puritana estuviera en la corte o en el campo; y que la alta burguesía oficial fuera tan básica como la intermedia o tan vistosa como la en ascenso. La alta burguesía asignada a la misma categoría frecuentemente actuaba con propósitos cruzados. [...] La solución para comprender los actos sociales de una élite [por consiguiente] no puede ser más sub-clasificación a partir de las categorías recibidas. Los meros modelos categóricos rara vez dividen a las personas en forma tal que se confirme con la acción observada, porque la actividad individual en el mundo se organiza a través de y motivada no por las afiliaciones categóricas sino por la estructura de las relaciones sociales tangibles en las que están insertas las personas" (Bearman, 1993: 9-10). 
en Scott, 1991). Estos métodos aparecen en forma destacada dentro del análisis de conjuntos como también en estudios de equivalencia estructural, las dos corrientes centrales en la investigación de redes sociales. ${ }^{32} \mathrm{El}$ primer enfoque centra la atención en los nexos directos e indirectos de los actores, para explicar procesos sociales a través del hecho mismo de la conectividad, como también a través de la fuerza, densidad y otras características, de los lazos que los unen. Busca especificar la centralidad relativa de actores en redes, la "importancia" de dichos actores y los subgrupos a los que pertenecen. "La estructura de redes se describe en términos de las relaciones típicas en las que los individuos están involucrados y el grado en el que están conectados los actores dentro de grupos primarios cohesivos como cliques" (Burt, 1980: 81). El último enfoque hace más énfasis en el conjunto de patrones de nexos de actores, no el uno con el otro, sino con terceros; la pregunta relevante aquí es la posición especifica o papel que cumple un conjunto de actores "estructuralmente equivalentes" en una red dada. "La estructura de redes se describe como entrelazada, conjuntos de status/papeles prestigiosos en forma diferenciada, en términos de los cuales los actores en un sistema están estratificados" (Burt, 1980: 81). Un procedimiento algebraico denominado "modelo en bloques" divide poblaciones completas en estas clases equivalentes. ${ }^{33}$

Los enfoques relacionales en el estudio sociológico de la cultura no están tan bien desarrollados como los relacionados con las redes sociales. Sin embargo, estas comparten muchos de estos supuestos básicos, comenzando con la noción que las formaciones culturales conllevan, no "actitudes" o "valores" individuales, mucho menos "sistemas" desincorporados, sino más bien paquetes de comunicaciones, relaciones o transacciones. Las metodologías relacionales entran al juego cuando se analizan las estructuras de significado que ordenan $\mathrm{u}$ organizan estos patrones. Dichas metodologías son transaccionales o relacionales precisamente porque involucran "un cambio en la forma de pensar el concepto como una expresión categórica única, y empezar a pensarlo como integrado en complejas redes relacionales que son tanto intersubjectivas como públicas. [...] Esto es, los conceptos no se pueden definir en sí mismos como entidades ontológicas únicas; más bien, el significado de un concepto se puede descifrar únicamente en términos de su 'lugar' en relación con los otros conceptos en su red. Lo que parecen categorías autónomas definidas por sus atributos son repensadas con mayor precisión como conjuntos de relaciones históricamente cambiantes que se estabilizan de manera contingente" (Somers, 1995: 136).

32 Los autores Emirbayer y Goodwin (1994), se referían a las corrientes "relacional” y "posicional", respectivamente- allí el término "relacional" tiene un significado diferente al del contexto presente.

33 Expresado en forma más precisa, los modelos en bloques comprueba la hipótesis de que un conjunto de relaciones se divide en un conjunto de clases equivalentes especificadas a priori. 
Estos aportes, por supuesto, son conocidos en la lingüística de Saussure y en la antropología estructural (Saussure, 1959; Lévi-Strauss, 1963), ambos con un énfasis eminentemente relacional en el cual el significado no proviene de las propiedades intrínsecas de los signos (entendidos como díadas "sonido-imagen" y "concepto", "significante" y "significado"), sino de sus diferencias con respecto a todos los demás signos dentro de un sistema semiológico. ${ }^{34}$ Tales ideas también son centrales en dos fuentes adicionales de la teoría semiótica, quizás menos conocidas pero tal vez más relacionadas con el pensamiento transaccional: la semiótica de Peirce y el dialogismo de Bakhtin. Charles Sanders Peirce, el fundador tanto del pragmatismo como de la semiotica, acepta la inserción relacional de los símbolos pero está muy en desacuerdo con la tradición Saussureana en tomar como unidad de análisis no las estructuras diádicas o visiones rápidas, sino más bien un proceso triádico de "signo", "objeto" e "intérprete": "Un signo [...] es algo que representa para alguien [el intérprete] algo [objeto] en algún respecto o capacidad. Se dirige entonces a alguien” (Peirce, 1931-58: 228). Como observa un comentarista, para Peirce "un signo únicamente tiene significado en el contexto de un proceso continuo de interpretación. Debido [a esto], su teoría es intrínsicamente procesal y por lo tanto incompatible con la teoría diádica e intrínsicamente estática de Saussure" (Rochberg-Halton, 1986: 46). Un enfoque procesal similar relacionado con el lenguaje y la cultura se puede encontrar en las obras de Mikhail Bakhtin, quien toma el "enunciado verbal" como punto de partida. Palabras, conceptos y símbolos derivan su significado únicamente de su ubicación dentro de enunciados verbales concretos; pero estos a su vez solo tienen sentido en relación con otros enunciados verbales dentro de flujos constantes de transacciones: "El enunciado verbal está lleno de sugerencias dialógicas. [...] Cada enunciado verbal individual es un eslabón en la cadena de la comunicación hablada [...] como la mónada de Leibnitz, [esta] refleja el proceso del habla, los enunciados verbales de los otros y, ante todo, los eslabones precedentes en la cadena" (Bakhtin, 1986: 92-93).

Los analistas de lo Cultural cada vez se inclinan más hacia estos enfoques relacionales en busca de una guía metodológica para el estudio de redes conceptuales o simbólicas. Mucha investigación empírica en antropología, historia y sociología, por ejemplo, recurre a las teorías semióticas mencionadas anteriormente, para analizar la lógica interna y las contradicciones de los lenguajes e idiomas culturales y los sistemas de significado. Programas de

34 También aquí es pertinente la obra seminal de Roman Jakobson: "A Jakobson lo atrajo el hecho de que para la física de Einstein, como para el Cubismo, todo tiene como base la relación. [...] El credo del artista 'No creo en las cosas, creo en su relación' (Georges Braque) así se unió al lema del matemático 'No son las cosas las que importan sino las relaciones entre ellas.' [...] O como el mismo Jakobson lo expresó mucho después 'Debe ponerse atención no a las unidades materiales en si mismas sino a sus relaciones' " (Waugh y Monville-Burston, 1990: 5). 
Investigación articulados por Jeffrey Alexander y Philip Smith (1993), Eugene Rochberg-Halton (1986) y Marc Steinberg (1996) ejemplifican estas perspectivas de Saussure (cum Lévi-Straussian), Peirce y Bakhtin, respectivamente. De una manera más formal, los investigadores también recurren a la sociolingüística para analizar las "comunidades de habla", o conjuntos de transacciones marcadas por el "conocimiento compartido de las restricciones comunicativas y opciones que gobiernan un gran número de situaciones sociales" (Gumperz, 1972: 16). ${ }^{35}$ Finalmente, ciertos analistas de la cultura no recurren a un análisis semiótico o lingüístico sino más bien a las estrategias relacionales de las redes sociales resumidas al principio. Una de estas líneas de trabajo incorpora un análisis de conjuntos o de conectividad, midiendo los nexos entre "conceptos focales" y otros símbolos dentro de "redes semánticas" en términos de su "densidad", "conductividad" y "consenso" (Carley y Kaufer ,1993; Carley, 1994). Otra línea de trabajo busca un enfoque de equivalencia estructural, usando los modelos de bloque para determinar la estructura formal de los "roles discursivos" o posiciones en los esquemas de clasificación, la retórica u otros conjuntos de prácticas culturales (Mohr, 1994). Unidas, estas líneas de investigación ofrecen abundantes técnicas para modelar la estructura interna de las formaciones culturales, técnicas que logran importantes resultados en niveles de investigación micro y macroscópicos. ${ }^{36}$

Los estudios relacionales de psicología social tal vez son los menos desarrollados en las tres categorías de investigación (pero véase Ritzer y Gindoff, 1992). Aquí el objeto de análisis son patrones psíquicos que restringen y posibilitan la acción por medio de la canalización de flujos e inversiones de energía emocional duradera, estructuras transpersonales de apego y solidaridad emocional, como también corrientes de hostilidad y agresión de contenido negativo. Las emociones, desde este punto de vista, no residen en "'entidades' que han sido colocadas en individuos, como 'personalidades' o 'actitudes,' " sino más bien en "formas situacionales de actuar en encuentros conversacionales" (Collins, 1981: 1010), esto es, en la dinámica transaccional. Las investigaciónes más significativas con esta orientación, aparecen dentro de la "nueva psicología social estructural". Randall Collins, por ejemplo, aduce que el aumento en los niveles de densidad física de las transacciones, junto con el incremento de un grupo, eleva el foco de atención del grupo y la intensidad de las emociones comunes. Para cualquier actor, la vida social consiste en una larga serie de estos rituales de interacción,

35 Ver también Halliday $(1976,1978)$ sobre "registros del habla" o modalidades compartidas del uso del lenguaje en una comunidad lingüísticas y Hanks (1990) sobre "géneros discursivos"; este último tiene mucha influencia de la teoría dialógica de Bakhtin.

36 También se debe mencionar aquí la obra de Bruno Latour (1987), quien combina el pensamiento relacional en los niveles de análisis socio-estructurales y culturales. 
"una cadena intermitente de rituales de interacción" (Collins, 1993: 210), con niveles de energía emocional que se acumulan gradualmente en todos ellos. Collins visualiza un mercado en la formación de tales rituales, con ciertas figuraciones que generan mayores estímulos a la energía emocional que otras, aunque algunas requieren mayores costos de entrada en el sentido de la "inversión" emocional. De esta forma, abre las posibilidades para esbozar la estructura de los flujos emocionales en el ámbito socio-psicológico más amplio. Las estructuras que realzan las interacciones rituales seguirían en paralelo, en este esbozo, a las figuraciones estructurales sociales y culturales de los otros dos contextos de acción relacionales. En la actualidad Collins está desarrollando nuevos programas de software para computadores para registrar gráficamente esto flujos emocionales con mayor especificidad.

Finalmente, los análisis relacionales de la autodinámica y la psicología individual se han vuelto cada vez más prevalentes. (Estas investigaciones aparecen en un nivel de análisis diferente del que se discutió previamente, el primero es personal y este último transpersonal por naturaleza.) Los estudios relacionales de la personalidad la conceptualizan no como rasgos fijos o disposiciones que perduran en el tiempo y en los contextos, sino más bien como la configuración estable de transacciones con "comportamientos característico de una situación-de si-entonces", o patrones de comportamiento característicos en circunstancias definidas pero significativamente similares. Mientras que la perspectiva sustancialista tradicional considera las situaciones como un "error" y busca diluir sus efectos sumándolos a la totalidad, el enfoque transaccional toma el patrón de compromiso del actor con las "situaciones de evocación" como su unidad básica de análisis. "Este cambio aleja la atención de inferencias sobre qué rasgos amplios tiene una persona, para enfocarse en lo que la persona hace en condiciones particulares durante el proceso de ajuste" (Mischel, 1990: 116). Una línea de investigación substantiva especialmente rica en estas "marcas de comportamiento" es la de Walter Mischel y sus asociados en una serie de estudios sobre niños en un campo de verano residencial. Por medio del análisis de las observaciones y de codificación en computador sobre el comportamiento de los niños (llevados a cabo por los consejeros del campo como también jueces independientes), estos investigadores encuentran "que existen patrones intraindividuales característicos de la forma en que [los niños/as] se relacionaban con las diversas condiciones psicológicas y que esos patrones forman una clase de firma de comportamiento que refleja coherencia de la personalidad" (Mischel y Shoda, 1995: 25 1). Mischel y sus asociados no esbozan estos patrones de comportamiento en forma sociométrica pero sus hallazgos en efecto los apuntan precisamente en esa dirección (ver White, 1994b). 


\section{Perplejidades, dificultades, retos}

Hasta ahora, he planteado y defendido la gran promesa de la teoría y la investigación transaccional, pero he dicho relativamente poco sobre los problemas que aun no se han resuelto totalmente dentro de ésta. A pesar de sus muchas e importantes contribuciones, esta perspectiva aún confronta muchas preguntas que no han sido resueltas. En la siguiente sección, analizaré los más significativos de estos problemas, tomando en cuenta los temas de límites y entidades, dinámica de redes, causalidad e implicaciones normativas.

El problema de la especificación de límites, el movimiento entre flujos de transacciones a unidades de estudio claramente demarcadas, de la continuidad a la discontinuidad, es tal vez el reto dentro del análisis relacional que se encuentra con más frecuencia. Los investigadores de las redes sociales, por ejemplo, continuamente tratan de resolver el problema de dónde trazar las líneas en redes relacionales que no poseen límites claros y naturales. Una pregunta análoga surge con respecto a las matrices culturales y socio-psicológicas. No se ha encontrado una solución definitiva para estas dificultades. ${ }^{37}$ De acuerdo con un conjunto de investigadores de redes, existen dos estrategias básicas para demarcar límites: la "realista" y la "nominalista". La primera asume el punto de vista de los actores involucrados, la red se trata "como un hecho social únicamente en el sentido de que se experimenta en forma consiente por los actores que lo componen". La segunda, por el contrario, proviene de los conceptos y propósitos del científico social que observa, tomando la correspondencia entre "los límites del investigador fijados en forma analítica y la conciencia subjetiva de estos límites establecidos por los participantes [como] una pregunta empírica en vez de un supuesto" (Laumann, Marsden y Prensky, 1983: 20-21). ${ }^{38}$ Así, el concepto de Bourdieu sobre un "campo de práctica" concuerda directamente con el lado "nominalista" de esta distinción: sus límites se fijan de acuerdo con el marco de referencia del observador (y no el de los participantes). La dificultad con el problema de los límites, por otra parte, se puede certificar en forma elocuente por la aparente circularidad en la propia "solución" que tiene Bourdieu este problema: "Podemos pensar en un campo como un espacio dentro del cual se ejerce un efecto del campo. [...] Los límites del campo se sitúan en el punto donde cesan los efectos

37 Para estudios sobre fijación de límites, ver Silverstein (1979), Zerubavel (1991) y Lamont y Fournier (1992). Ronald Breiger anota que (comunicación personal, 11 de Julio de 1996) que un "enfoque [...] es para internalizar o endogenizar o 'reflexionar sobre' este problema dentro del marco de un análisis relacional. [entonces] los límites (sustancialistas) se enfrentan a los límites definidos por relaciones”. Encuentre ejemplos substantives en Breiger (1981).

38 Laumann, et al. (1983) añade que además se pueden distinguir tres enfoques (cada uno con su respectiva metodología) que trascienden las dos estrategias que se acaban de mencionar para determinar si los actores dados se incluirán dentro de un límite: posesión de atributo específico; participación en tipo específico de relación; o participación en eventos o actividades determinados. 
del campo" (Bourdieu y Wacquant, 1992: 100). Al comenzar con la ramificación de redes de relaciones en vez de sustancias, se vuelve notoriamente difícil justificar los límites empíricos que deseamos fijar.

Tras las dificultades analíticas y metodológicas en la fijación de límites, también hay preguntas fundamentales de naturaleza ontológica. Después de definir los límites en torno a una matriz de transacciones específica, ¿cómo se puede caracterizar lo que se obtiene dentro de esos límites? ¿Cuando, si alguna vez ocurre, realmente un conjunto de relaciones tiene valor como "cosa", sustancia o entidad? En Identity and Control, Harrison White (1992) señala que los conjuntos (aunque no todos) de eventos o transacciones se pueden considerar entidades. Una entidad o "identidad", afirma él, es "cualquier fuente de acción no explicable a partir de regularidades biofísicas y a las que los observadores les pueden atribuir significado. [...] Los conjuntos se pueden llegar a percibirse y a actuar como identidades, si reaparecen en forma repetida o en una diversidad de otros contextos" (White, 1992: 6-7). Andrew Abbott (1996) aclara aún más que no todas las "zonas de diferencia" dentro de un proceso social o espacio social se convierten en entidades; la "entividad" (Campbell, 1958) de un fenómeno recurrente consiste en la posibilidad de que exhiba dos características claves: "coherencia", alguna estructura de causas internas del fenómeno que le permite la recurrencia, para "seguir ocurriendo en la misma forma" y "autoridad causal", una "posición independiente como sitio de causación, como una cosa con consecuencias [...] [una habilidad] para crear un efecto sobre el resto del proceso social que va más allá de los efectos [...] tan solo transmitido por medio de la entidad causante" (Abbott, 1996: 873). La dificultad, por supuesto, es que ninguno de los elementos en la definición de Abbott se puede ver como supuesto en una ontología procesal; sin embargo, ambos deben explicarse. Identidades y entidades son conceptos problemáticos dentro de los enfoques transaccionales en formas en los que nunca podrán ser dentro de un modo de análisis sustancialista. ${ }^{39}$

Muy relacionado con el problema de los límites e identidades está el de la dinámica de redes. Paradójicamente (para un modo de estudio tan enfocado en la procesalidad), la sociología relacional tiene mayor dificultad en analizar, no las características estructurales de redes estáticas, ya sean culturales, socio-

39 En otras palabras hay una compensación inevitable de los "problemas" concomitantes cuando se cambia del puntos de vista sustancialista al relacional: "Al hacer del cambio nuestra constante, también intercambiamos lo que queremos explicar. Se vuelve necesario explicar la reproducción, la constancia y la "entividad”, en vez del desarrollo y el cambio". En forma más concisa, Abbott continúa, "la razón central para hacer este [cambio] es práctico. Es posible explicar la reproducción como un fenómeno que a veces lo produce el cambio perpetuo; no es posible explicar el cambio como fenómeno producido algunas veces por la estasis perpetua" (Abbott, 1997: 98). Es difícil imaginar una articulación más concisa y persuasiva de las ventajas relativas de las perspectivas transaccionales frente a las sustancialistas. 
estructurales o socio-psicológicos, sino más bien en el análisis de procesos dinámicos que de alguna forma transforman esas matrices de transacciones. Aún los estudios de "procesos-relacionales", a menudo privilegian lo espacial (o ubicación topológica) por encima del desarrollo de la temporalidad y la narrativa. ${ }^{40}$ (Esta lógica probablemente se puede relacionar con la misma hegemonía del sustancialismo que hace que los enfoques auto e interaccionales tengan tanta relevancia.) Además, las "salidas" más prometedoras provienen del análisis relacional de las estructuras sociales. Por ejemplo, en su investigación sobre "agujeros estructurales", Ronald Burt (1992) examina las circunstancias que maximizan la "autonomía estructural", la capacidad de explotar de forma efectiva cualquier información y los beneficios de control que pueden permitirse dentro de una red. ${ }^{41} \mathrm{El}$ concepto de Burt es que lo que mejor explica la acción no son los atributos de los mismos actores sociales, sino las figuraciones complejas de relaciones (especialmente las relaciones de ausencia o "agujeros") a las que éstas responden. (En principio, argumentos paralelos también podrían desarrollarse con respecto a figuraciones culturales y socio-psicológicas.) En un estudio de redes más amplio, John Padgett y Christopher Ansell (1993) combinan esta noción de autonomía estructural con un enfoque en la "acción robusta", el "oportunismo flexible" hecho posible por ciertos actores, las ubicaciones "estructuralmente anormales" dentro de redes sociales marcadas por agujeros estructurales profundos. Aún otros analistas (por ejemplo, Gould y Fernandez, 1989) examinan los papeles cruciales que juegan los "agentes" en los procesosen-relación. Todos estos investigadores convergen en la idea de que la dinámica de redes está dialécticamente relacionada a las estructuras de redes y cada uno de estos "momentos" está parcialmente condicionando por el otro.

Sin embargo, Harrison White está llevando a cabo otra investigación sobre los procesos dinámicos; su principal contribución ha sido la de alejar la atención analítica de las redes sociales hacia unidades socioculturales que él denomina "dominios de red" o "por su abreviatura en inglés, netdoms". (White

40 Para un caso clásico de este tipo, ver el célebre artículo sobre los modelos en bloque de White, Boorman y Breiger (1976), que no ofrece más que una mera sucesión de representaciones estáticas (o “vistazos”) de la estructura social. (Para un análisis crítico, ver Emirbayer y Goodwin, 1994). Enfoques más recientes (por ejemplo, el número especial sobre dinámica de redes publicado por Journal of Mathematical Sociology [1996]) ofrece emocionantes innovaciones técnicas pero que no resuelven satisfactoriamente el problema. Entre tanto, en el área del análisis cultural se puede decir casi lo mismo del estructuralismo de Claude Lévi-Strauss (1963), que se apoya en forma muy explícita en una dicotomía conceptual de estructura y tiempo.

41 De acuerdo con su definición, "Los jugadores con relaciones libres de agujeros estructurales en su propio extreme y rico en agujeros estructurales en el otro extremo son estructuralmente autónomos” (Burt, 1992: 45). 
habla relativamente poco sobre la formación socio-psicológica). ${ }^{42}$ Los actores continuamente "cambian" entre netdoms a medida que negocian transiciones sutiles, a veces a duras penas perceptible, entre las varias formas de interacción social que marca la cotidianidad. Lo "público", de lo cual el breve "receso para el café" es un simple ejemplo, facilita estas transiciones; en ellas, los tiempos sociales y los significados relacionados con ámbitos específicos de redes se suspenden y los mismos dominios de red se "desacoplan" el uno del otro en un tipo de "burbuja temporal" de "tiempo presente continuo". ${ }^{43}$ Los cambios también ocurren dentro de los netdoms, entre las varias "historias" o recuentos de la realidad social que se han creado juntos y sirven para constituir cada uno de los dominios de red. "En las relaciones sociales ordinarias y normales", escribe White, "se están arrastrando muchas versiones alternativas hasta que ocurran las resoluciones temporales en las disyunciones que yo llamo cambios. En una operación de cambio, el malabarismo continuo en el conjunto de historias se resuelve en el relato a partir del cual se inicia la siguiente fase de construcción de realidad, entre relaciones articuladas a través del allí y el entonces" (White, 1996: 1049). Aquí White invoca a partir de la ciencia estadística la idea de "bifurcaciones bayesianas" para capturar la incertidumbre o ambigüedad — “Qué está pasando aquí?”- que surge y se resuelve dentro de los cambios de redes. Por medio de estas categorías fenomenológicas, White ayuda a aumentar nuestra comprensión de los mecanismos que hace que funcionen los procesos de redes. Lo que aún falta en su relato, por otra parte (al igual que en otros enfoques sobre la dinámica de redes resumidos anteriormente), es alguna consideración sistemática y normativa del papel que Dewey denominó "inteligencia” en la guía y dirección intencional de los asuntos humanos. El compromiso reflexivo de los actores sociales con los problemas a los que se enfrentan en su cotidianidad permanece significativamente poco teorizado en los estudios recientes sobre procesos de redes (este tema también se tratara a continuación).

Un tercer reto relacionado y enfrentado por el enfoque relacional se refiere a la causalidad. ¿Cómo se puede explicar la dinámica de redes? ¿Cómo se pueden explicar los cambios en el contenido y dirección de los flujos transaccionales? Un problema persistente, a pesar de ser una consecuencia de la forma de razonamiento sustancialista, es la tendencia aún de muchos pensadores relacionales a describir las causas como fenómenos inmateriales. Se dice que entidades como "fuerzas",

42 "Las redes toman especialmente los patrones transversales de conexión y resonancia en la interacción. Los dominios toman especialmente los significados y las interpretaciones, que son la fenomenología de procesos como conversación. Estos dos, redes y dominios, se juntan en una clase de lazo y [...] para la construcción de significados sociales y tiempos” (White, 1996: 1038).

43 El público facilita los cambios porque "es más fácil evolucionar una simple 2 n veces para entrar y salir de un estado público común desde $\mathrm{n}$ dominios de redes diferentes que evolucionar un mayor (n veces $\mathrm{n}-1)$ número de veces para cambiar de uno a otro de los dominios de redes” (White, 1996: 1056). 
"factores" y "estructuras" "impulsan" las sustancias sociales, que incluyen personas y grupos, hacia el camino causal. Aún las figuraciones o patrones de relaciones (que incluyen agujeros estructurales) se vuelven sustantivos que supuestamente "mueven" la acción de alguna manera. ¿Puede la causalidad conceptualizarse en forma más satisfactoria? Un escritor comienza a enfrentar este problema proponiendo un nuevo "lenguaje de acción" para las ciencias sociales. Roy Schafer (1976), un teórico del psicoanálisis, propone "que consideremos cada proceso, evento, experiencia o comportamiento psicológico [y, por extensión, social] como alguna clase de actividad y por consiguiente llamarla acción y [...] llamar a cada acción con un verbo activo que exponga su naturaleza y por un adverbio (o locución adverbial) cuando aplique, que exponga el modo de esta acción. El adoptar esta regla conlleva a que, en la medida de lo posible y con sensatez, no se usarán nombres y adjetivos para referirse a procesos, eventos, etc [transaccionales]". (Schafer, 1976: 9). Por lo tanto, una oración como "su posición desventajosa condujo a un aumento en la competitividad" deberá traducirse como "ellos respondieron a su desventajosa situación actuando en forma más competitiva". Los actores sociales mismos, en transacciones lúdicas dentro de contextos siempre cambiantes, llevan a cabo toda la actuación en la vida social, no son unas entidades imaginarias dentro o sin ellos, como en las visiones globales sustancialistas de la acción auto-orientada o de la interacción.

Por supuesto, una guía metodológica como ésta sigue siendo útil sólo en la medida en que tengamos en cuenta que no todos los actores sociales son personas individuales: en ciertos contextos, organizaciones u otras identidades también podrían considerarse actores para propósitos del análisis transaccional. Más importante aún, los actores sociales siempre están insertos en el espacio y en el tiempo; responden a situaciones específicas (oportunidades y restricciones) en vez de buscar líneas de conducta puramente solipsísticas. Las narrativas de sus respuestas (junto con las situaciones en las que éstas ocurren) ayudan a explicar la forma en que las causas en realidad producen efectos en la historia. El lenguaje de acción, en otras palabras, allana el terreno para que el análisis causal elimine estructuras cosificadas como "factores causales", pero es necesario complementarlas con una preocupación por los "mecanismos situacionales" (Stinchcombe, 1991) que en realidad canalisan los flujos de eventos. Estos mecanismos ofrecen una respuesta a aquellos que sugerirían (como, por ejemplo, a menudo lo hacen los analistas con un enfoque en el estudio de variables) que el lenguaje de acción abandona la búsqueda de generalidades causales dentro de la vida social. Tilly ofrece un ejemplo de la clase de mecanismo que ahora podríamos estar buscando: "La relación entre una actividad, el conjunto de agentes que controlan los medios que podrían hacer posible esa actividad y la 
negociación que ocurre entre los agentes de la actividad y los que poseen los recursos, produce conjuntos de estructuras inesperadas que restringen la siguiente ronda de acción. [...] El mecanismo causal se encuentra en la negociación que resulta de la resistencia a liberar los recursos que ya están comprometidos con otros objetivos. [...] La causa general se encuentra en la lucha por el control de los recursos deseados" (Tilly, 1993: 6). Este enfoque hacia la causalidad conserva la orientación hacia la acción que defiende Schafer, aunque evita la tendencia de éste último hacia el voluntarismo puro al insistir en una búsqueda de procesos explicativos sólidos que operan en una multiplicidad de situaciones sociales.

Finalmente, las implicaciones normativas de la investigación relacional se ponen en duda cuando se considera la clase de moral y apalancamiento práctico que podría ofrecer este tipo de investigación con respecto a las realidades sociales. Podemos distinguir aquí entre implicaciones "críticas" y "reconstructivas". Preeminentes entre las primeras está la capacidad, amparada por el pensamiento transaccional, para "descongelar" las categorías estáticas sustancialistas que niegan la fluidez - por consiguiente, la mutabilidad - de los patrones figuracionales. En los estudios culturales actuales, por ejemplo, los modos de pensamiento "esencialistas" ven con demasiada frecuencia a los individuos y a las colectividades como dotadas de "identidades" singulares y unitarias arraigadas en raza, clase, género o sexualidad; supuestamente, estas características atributivas explican sin problema los "intereses" y la acción. ${ }^{44}$ Este esencialismo tampoco se limita solamente al análisis cultural; la "política de identidad" contemporánea en buena parte gira alrededor de intentos similares para tematizar (y legitimar) identidades colectivas particulares (por ejemplo, "afro-americana", "mujer latina") devaluadas durante mucho tiempo en la cultura dominante. Esencialismos más claramente perniciosos (por ejemplo, racismo, [hetero-] sexismo, nacionalismo xenófobo) comparten ese razonamiento, aunque no estén en su agenda ideológica progresiva. Ahora, las categorías en realidad tienen gran importancia en la vida social; como lo señaló W. I. Thomas en su muy conocida cita: "Si los hombres definen las situaciones como reales, éstas son reales en sus consecuencias" (Thomas y Thomas, 1928: 572). Además, el pensamiento categórico puede tener implicaciones cruciales críticas, como normalizar categorías previamente devaluadas o redistribuir recursos por medio de políticas sociales. Sin embargo, el pensamiento transaccional refuta la naturaleza intrínsecamente cosificada de todas las categorías: demuestra la forma en que "totalizan" las identidades que de hecho a menudo son multidimensionales y contradictorias; prescribe modos

44 Las versiones de los estudios culturales que hablan en términos más matizados de la intersección de identidades múltiples, como en la categoría de "lesbianas negras", añaden una complejidad considerable al panorama; sin embargo, aún no escapan de las dificultades que pertenecen a todos los pensamientos categóricos sustancialistas. 
de pensamiento y acción en contra de los cuales las alternativas únicamente se pueden catalogar como "anormales"; naturaliza las distinciones rígidas que suprimen posibilidades a la (auto) transformación creativa; y, en forma más general, acepta en vez de refutar las matrices relacionales históricamente variables que sirven para constituir distinciones y categorías injustas en primer lugar (Somers y Gibson, 1994: 55-57). ${ }^{45}$ El pensamiento transaccional, en una palabra, de-construye un universo moral que se da por sentado; al hacer esto, ataca en la vida moral y práctica las mismas tendencias hacia la "reducción-de- procesos" que Elias tan vigorosamente subrayaba a nivel de cognición. ${ }^{46}$

En un sentido más de tipo reconstructivo, el razonamiento relacional también se dirige directamente al problema sobre qué línea de conducta contaría como "mejor" o "peor" (o como punto final de la acción), desde un punto de vista ético o político. Si los valores no son sustancias pre-constituidas, entonces ¿¿de dónde surgen y cómo se les debe evaluar? ¿Qué clases de transacciones deben tener el valor más alto en la visión procesal y relacional del mundo? Estos temas, que han desconcertado durante mucho tiempo a los teóricos transaccionales, tal vez tratado en su forma más provocativa por algunos pragmatistas clásicos, como el estadounidense John Dewey - con quien abrimos este articulo- y George Herbert Mead (también se interesaron en formas similar teóricos como Bakhtin, 1993 y más adelante en Jürgen Habermas, 1984-871). Para los pragmatistas, las implicaciones normativas fluyen naturalmente fuera del concepto central de la transacción misma: "Los valores no son simplemente presuposiciones objetivas, independientes de la existencia humana. Sin embargo, tampoco es meramente el producto de la evaluación subjetiva de objetos que son esencialmente neutros con respecto a esta evaluación. Más bien [...] la evaluación es el resultado de una 'interacción' [o transacción] de sujeto y objeto" (Joas, 1985: 131). Por lo tanto, los valores son subproductos del compromiso mutuo de los actores en circunstancias ambiguas y desafiantes, que surgen cuando las personas experimentan un desacuerdo en los alegatos de múltiples compromisos normativos. Las situaciones problemáticas de esta clase se resuelven únicamente cuando los actores reconstruyen los contextos relacionales en los que están

45 Ver el número 38, arriba. En la política práctica y la lucha cultural, a menudo los actores sociales invocan estratégicamente identidades colectiva, aún a medida que ponen en duda teóricamente el pensamiento categórico. "El punto [...] no es dejar de estudiar la formación de identidades o hasta abandonar todas las formas de las políticas de identidades, sino más bien [...] depender de las nociones de identidad y de las políticas de identidades por su utilidad estratégica mientras permanece vigilante contra la reificación” (Epstein, 1994:197).

46 Para ejemplos de pensamiento auto-conscientemente deconstruccionista, "post-estructuralista” con respecto a las preguntas sobre identidad, ver Scott (1988) y Sedgwick (1990). El relacionalismo de ninguna manera conlleva la adopción de todos los aspectos del deconstruccionismo, aún si comparte con éste características importantes. Las continuidades (y discontinuidades) entre deconstruccionismo (Derrida, 1974), por una parte, y las perspectivas relacionales contemporáneas del neo-pragmatismo (especialmente Rorty, 1982) a la teoría de las redes sociales- (especialmente White, 1992), por otra parte-se prestarían para un estudio comparativo valioso. 
insertos y en el proceso, transforman sus propios valores y se transforman a ellos mismos: "La aparición de [...] diversos intereses en el foro de reflexión [lleva a] la reconstrucción del mundo social y la consiguiente aparición de la nueva identidad que responde al nuevo objeto" (Mead, 1964: 149).

Visiones atractivas tanto de acción como de orden siguen directamente esta línea de razonamiento. La solución racional de situaciones-problema - un asunto de acción - requiere capacidades de razonamiento prudentes y juicios prácticos, lo que los pragmatistas (comenzando con Dewey) denominaron "inteligencia”. En este modo de acción, "el individuo [...] tiene[n] en cuenta todo esos intereses [que están implicados en una situación dada] y luego elabora[n] un plan de acción que se encargará de forma racional de esos intereses" (Mead, 1934: 388; ver Emirbayer y Mische, en prensa). El actor se pone en el lugar del otro, amplía su propio punto de vista por medio del compromiso argumentativo con este último y así logra perspectivas aún más globales, cosmopolitas y universales. En forma paralela, el modo ideal de compromiso o transacción mutuo - un asunto de orden- conlleva a la comunicación abierta y libre entre actores en una comunidad universal, una matriz relacional en la que tanto la cooperación como el conflicto se regulan racionalmente. Este "modo de vivir en forma asociada - en una palabra, la democracia encarna la inteligencia moral en una escala transpersonal; involucra una "experiencia conjunta comunicada" en la que el razonamiento práctico se lleva a cabo en forma comunitaria, por medio de la investigación sobre problemas morales y políticos con el modelo de una ciencia experimental (Dewey, 1980: 93). Este punto de vista - que pertenece tanto la acción como al orden- logra resolver muchos problemas relacionados con las implicaciones normativas del razonamiento relacional, sin desbordar en ningún momento el marco de referencia transaccional. Sin embargo, lo que no trata en forma adecuada es la pregunta sobre si los estándares del juicio normativo deben ser sustantivos o meramente de procedimiento: ¿Es que la idea de una comunicación libre y abierta en procesos transaccionales no significa nada distinto de un método formal de razonamiento inteligente o es que acaso apunta a una visión más satisfactoria sobre el carácter moral y los acuerdos sociales colectivos? Este es un problema que sigue preocupando a los pensadores relacionales (a tal punto que todos lo abordan en algún grado) y que aún no han logrado - y puede que nunca logren- resolverlo en forma satisfactoria. ${ }^{47}$

47 Hasta ahora una de las deficiencias más graves de la sociología relacional es su escaso interés en las preocupaciones normativas, a pesar de la profunda interpenetración (de modo verdaderamente transaccional) de todas las preguntas sobre el "ser" y el "deber ser" en el análisis social-científico. 


\section{Conclusión}

Estos temas y problemas aún sin resolver, a pesar de la posibilidad de un modo relacional de investigación sociológica, siguen siendo muchos. Filosóficamente, teóricamente y empíricamente este método de investigación ofrece una alternativa convincente a las perspectivas de auto e interacción, hoy en ascenso, y a los defensores reconocidos en la sociología: selecciones racionales, neo-kantianas, estructuralistas y fundamentadas en variables. Enfoques nuevos y emocionantes dentro de los análisis culturales, socio-estructurales y socio-psicológicos ya ejemplifican este amplio potencial; de hecho, los esfuerzos actuales por reconstruir los principales conceptos teóricos así lo demuestran. Además, los pensadores sociales provenientes de una amplia variedad de formaciones disciplinarias, tradiciones nacionales y puntos de vista analíticos y empíricos están rápidamente convergiendo en este marco de referencia, a menudo sin siquiera captar su significado total. Un conjunto de supuestos - que algunos podrían denominar un paradigma - que inicialmente se refería a la expresión sistemática en la teoría sociológica, al igual que en otros campos como la física, a comienzos del siglo veinte (por supuesto, sus antecedentes se remontan a mucho antes); finalmente ahora, a finales de este siglo, estos supuestos comienzan a recibir la atención general que tanto se merecen. A pesar de la atención que se le presta a tantos otros debates, dualismos y oposiciones en sociología, la elección entre los modos de investigación sustancialista y relacional, una escogencia entre supuestos básicos con respecto a la naturaleza misma de la realidad social, rápidamente se está convirtiendo en la línea divisoria más importante y trascendentales en la investigación sociológica.

Hay muchos retos para el futuro; en la sección anterior se discutieron únicamente unos de los más significativos. Los teóricos e investigadores relacionales ahora deben enfocarse en varias tareas. Una de ellas es explorar aún más agresivamente los niveles analíticos de la cultura y las emociones colectivas, importando hacia estas áreas muchos conceptos y técnicas de investigación ya elaboradas por los analistas de redes, pero también explotando por ejemplo, los nuevos y apasionantes enfoques desarrollados por los investigadores de sociolingüística y socio-psicología. (Los analistas se han estado moviendo hacia el campo de la cultura en números cada vez mayores; sin embargo, hasta ahora el estudio de los flujos emocionales transpersonales - la dimensión socio-psicológica- ha permanecido muy subdesarrollado.) Segundo y de forma relacionada, los investigadores transaccionales deben esforzarse decididamente para mantener una consistencia teórica en todos los niveles de análisis, no solamente en sus explicaciones más específicas según el caso, sino también y especialmente, en sus esfuerzos generales que buscan la construcción de una 
teoría. Frecuentemente la cautela de los pensadores dentro del ámbito social con respecto a la teorización exhaustiva (¿un residuo sin vigencia de batallas previas contra el legado Parsoniano?) induce una aceptación demasiado fácil de modelos híbridos (por ejemplo, yuxtaposiciones del enfoque del actor racional y el enfoque de análisis de redes). La riqueza y amplitud de las formas relacionales de pensamiento nos permiten evitar este razonamiento ad hoc $y$ desarrollar explicaciones causales en forma más deliberada dentro de un marco de referencia unificado. Finalmente, los pensadores transaccionales deben comenzar a sistematizar algunas de las formas alternas en las cuales los asuntos y problemas centrales se han tematizado desde su propia tradición. Los debates internos se elevarán a un plano mucho más elevado - y facilitaran la construcción de teorías después que los analistas comiencen a ver diferencias, por ejemplo, entre Bourdieu y Foucault sobre "poder", entre Tilly y Somers sobre "cultura" o entre Dewey y White sobre "inteligencia", como formas alternativas de proceder desde las mismas premisas filosóficas relacionadas con los procesos-en-relaciones. Únicamente entonces los sociólogos transaccionales podrán captar plenamente las posibilidades y opciones que los confrontan; solo entonces lograrán (y en forma más general la disciplina sociológica) finalmente la claridad teórica y la reflexividad que desde mucho tiempo atrás habrían podido lograr. ${ }^{48}$

\section{Referencias bibliográficas}

-Abbott, Andrew. 1988. "Transcending General Linear Reality." Sociological Theory 6:169-86.

1992a. "What Do Cases Do? Some Notes on Activity in Sociological Analysis." Pp. 53-82 in What Is a Case? Exploring the Foundations of Social Inquiry, edited by Charles C. Ragin and Howard S. Becker. Cambridge: Cambridge University Press.

. 1992b. "Of Time and Space: The Contemporary Relevance of the Chicago School." Sorokin Lecture, delivered at the meeting of the Southern Sociological Society.

1996. "Things of Boundaries." Social Research 622357-82.

48 A menos que este “manifiesto” parezca incompleto sin uno, este es el grito de ánimo final: ¡Entidades del Mundo:Vinculaos! Esta afirmación tanto descriptiva como prescriptiva, con implicaciones causales y normativas (a pesar de los ligeros matices interactuantes) captura muy bien las ricas posibilidades inherentes a la visión de la realidad social relacional, transaccional. 
16: 85-105.

. 1997. "On the Concept of Turning Point." Comparative Social Research

-Alexander, Jeffrey C. 1983. Theoretical Logic in Sociology. Vol. 4, The Modern Reconstruction of Classical Thought: Talcott Parsons. Berkeley and Los Angeles: University of California Press.

1988. Action and Its Environments: Toward a New Synthesis. New York: Columbia University Press.

-Alexander, Jeffrey C., and Philip Smith. 1993. "The Discourse of American Civil Society: A New Proposal for Cultural Studies." Theory and Society 22:151207.

-Bakhtin, Mikhail M. 1986. “The Problem of Speech Genres.” Pp. 60-102 in Speech Genres and Other Late Essays, edited by Caryl Emerson and Michael Holquist. Translated by Vern W. McGee. Austin: University of Texas Press.

1993. Toward a Philosophy of the Act, edited by Vadim Liapunov and Michael Holquist. Translated by Vadim Liapunov. Austin: University of Texas Press.

-Bates, Frederick L., and Walter Gillis Peacock. 1989. "Conceptualizing Social Structure: The Misuse of Classification in Structural Modeling." American Sociological Review 54:565-77.

-Bauman, Zygmunt. 1989. "Hermeneutics and Modern Social Theory." Pp. 3455 in Social Theory of Modern Societies: Anthony Giddens and His Critics, edited by David Held and John B. Thompson. Cambridge: Cambridge University Press.

-Bearman, Peter S. 1993. Relations into Rhetorics: Local Elite Social Structure in Norfolk, England, 1540-1640. New Brunswick, N.J.: Rutgers University Press.

-Benhabib, Seyla. 1992. Situating the Self: Gender, Community and Postmodernism in Contemporary Ethics. New York: Routledge.

-Benjamin, Jessica. 1988. The Bonds of Love: Psychoanalysis, Feminism, and the Problem of Domination. New York: Pantheon. 
-Bernstein, Richard J. 1966. John Dewey. Atascadero, Calif.: Ridgeview.

-Bourdieu, Pierre, and Loi'c J. D. Wacquant. 1992. An Invitation to Reflexive Sociology. Chicago: University of Chicago Press.

Breiger, Ronald L. 1974. "The Duality of Persons and Groups." Social Forces 53:181- 90 .

1981. "The Social Class Structure of Occupational Mobility." American Journal of Sociology 87578-61 1. 1990. "Social Control and Social Networks: A Model from Georg Simmel.” Pp. 453-76 in Structures of Power and Constraint: Papers in Honor of Peter M. Blau, edited by Craig Calhoun, Marshall W. Meyer, and W. Richard Scott. Cambridge: Cambridge University Press.

1991. Explorations in Structural Analysis: Dual and Multiple Networks of Social Interaction. New York: Garland. Burt, Ronald S. 1980. "Models of Network Structure." Annual Review of Sociology 6:79-141.

1992. Structural Holes: The Social Structure of Competition. Cambridge, Mass.: Harvard University Press.

-Campbell, D. T. 1958. "Common Fate, Similarity, and Other Indices of the Status of Aggregates of Persons as Social Aggregates." Behavioral Science 3:1425.

-Carley, Kathleen M. 1994. "Extracting Culture through Textual Analysis." Poetics 22:291-312.

—Carley, Kathleen M., and David S. Kaufer. 1993. "Semantic Connectivity: An Approach for Analyzing Symbols in Semantic Networks." Communication Theory 3: 183-2 13.

-Cassirer, Ernst. 1953. Substance and Function, translated by William Curtis Swabey and Marie Collins Swabey. New York: Dover.

-Chodorow, Nancy J. 1978. The Reproduction of Mothering: Psychoanalysis and the Sociology of Gender. Berkeley and Los Angeles: University of California Press. 
. 1989a. "Toward a Relational Individualism: The Mediation of Self through Psychoanalysis." Pp. 154-62 in Feminism and Psychoanalytic Theory. New Haven, Conn.: Yale University Press.

. 1989b. Feminism and Psychoanalytic Theory. New Haven, Conn.:

Yale University Press.

-Colapietro, Vincent M. 1990. "The Vanishing Subject of Contemporary Discourse: A Pragmatic Response.” Journal of Philosophy 87:644-55.

-Collins, Randall. 1981. "On the Microfoundations of Macrosociology." American Journal of Sociology 86:984-1014.

. 1993. "Emotional Energy as the Common Denominator of Rational Action." Rationality and Society 5:203-30.

-Commons, John R. 1924. Legal Foundations of Capitalism. New York: Macmillan.

-Cooley, Charles Horton. 1962. Social Organization: A Study of the Larger Mind. New York: Charles Scribner’s Sons.

-Derrida, Jacques. 1974. Of Grammatology, translated by Gayatri Chakravorty Spivak. Baltimore: Johns Hopkins University Press.

-Dewey, John. 1929. Experience and Nature. La Salle, Ill.: Open Court.

1980. Democracy and Education. The Middle Works of John Dewey, 1899- 1924, vol. 9. Edited by Jo Ann Boydston. Carbondale, Ill.: Southern Illinois University Press.

-Dewey, John, and Arthur F. Bentley. 1949. Knowing and the Known. Boston: Beacon Press.

-Durkheim, Emile. 1995. The Elementary Forms of Religious Lge, translated by Karen E. Fields. New York: Free Press.

-Elias, Norbert. 1978. What Is Sociology? translated by Stephen Mennell and Grace Morrissey. New York: Columbia University Press. 
-Elster, Jon. 1989. Nuts and Bolts for the Social Sciences. Cambridge: Cambridge University Press.

-Emirbayer, Mustafa. 1996. "Useful Durkheim." Sociological Theory 14: 10930.

-Emirbayer, Mustafa, and Jeff Goodwin. 1994. "Network Analysis, Culture, and the Problem of Agency." American Journal of Sociology 99: 1411-54.

. 1996. "Symbols, Positions, Objects: Toward a New Theory of Revolutions and Collective Action." History and Theory 35: 358-74.

1997. "Positions, Symbols, Objects: A Relational Theory of Social Action and Historical Change." Manuscript. New School for Social Research, Department of Sociology.

-Emirbayer, Mustafa, and Ann Mische. 1998. "What Is Agency?" American Journal of Sociology 103(4): 962 - 1023.

-Emirbayer, Mustafa, and Mimi Sheller. 1996. "Publics in History: A Programmatic Statement." Paper presented at the meeting of the Social Science History Association, New Orleans.

-Epstein, Steven. 1994. "A Queer Encounter: Sociology and the Study of Sexuality." Sociological Theory 12: 188-202.

-Foucault, Michel. 1979. Discipline and Punish: The Birth of the Prison, translated by Alan Sheridan. New York: Vintage Books.

1990. The History of Sexuality. Vol. 1, An Introduction, translated by Robert Hurley. New York: Vintage Books.

-Gergen, Kenneth J. 1994. Realities and Relationships: Soundings in Social Construction. Cambridge, Mass.: Harvard University Press.

-Goffman, Erving. 1967. Interaction Ritual: Essays on Face-to-Face Behavior. New York: Pantheon.

-Goodwin, Jeff. 1995. "A Case for Big Case Comparison." Comparative Historical Sociology Newsletter 8:1, 6. 
—Gould, Roger V., and Roberto M. Fernandez. 1989. "Structures of Mediation: A Formal Approach to Brokerage in Transaction Networks." Sociological Methodology 19189-126.

-Gumperz, John J. 1972. Introduction to Directions in Sociolinguistics, edited by John J. Gumperz and Dell Hymes. New York: Holt, Rinehart, \& Winston.

-Habermas, Jurgen. 1983. "Hannah Arendt: On the Concept of Power." Pp. 173-89 in Philosophical-Political Projiles, translated by Frederick G. Lawrence. Cambridge, Mass.: MIT Press.

1984-87. The Theory of Communicative Action, 2 vols. Translated by Thomas McCarthy. Boston: Beacon Press.

-Halliday, M. A. K. 1976. System and Function in Language: Selected Papers, edited by G. R. Kress. London: Oxford University Press.

. 1978. Language as Social Semiotic: The Social Interpretation of Language and Meaning. London Edward Arnold.

-Hanks, William F. 1990. Referential Practice: Language and Lived Space among the Maya. Chicago: University of Chicago Press.

-Husserl, Edmund. 1960. Cartesian Meditations: An Introduction to Phenomenology, translated by Dorion Cairns. The Hague: Martinus Nijhoff.

-James, William. 1976. Essays in Radical Empiricism. Cambridge, Mass.: Cambridge University Press.

-Joas, Hans. 1985. G. H. Mead: A Contemporary Re-examination of His Thought, translated by Raymond Meyer. Cambridge, Mass.: MIT Press.

1993. Pragmatism and Social Theory. Chicago: University of Chicago

Press.

1996. The Creativity of Action, translated by Jeremy Gaines and Paul Keast. Chicago: University of Chicago Press. 
-Knoke, David. 1990. Political Networks: The Structural Perspective. Cambridge: Cambridge University Press.

-Kreps, David M. 1990. Game Theory and Economic Modelling. New York: Oxford University Press.

-Lamont, Michkle, and Marcel Fournier, eds. 1992. Cultivating Differences: Symbolic Boundaries and the Making of Inequality. Chicago: University of Chicago Press.

-Latour, Bruno. 1987. Science in Action: How to Follow Scientists and Engineers through Society. Cambridge, Mass.: Harvard University Press.

-Laumann, Edward O., Peter V. Marsden, and David Prensky. 1983. "The Boundary Specification Problem in Network Analysis." Pp. 18-34 in Applied Network Analysis: A Methodological Introduction, edited by Ronald S. Burt and Michael J. Minor. Beverly Hills, Calif.: Sage.

-Lévi-Strauss, Claude. 1963. Structural Anthropology, translated by Claire Jacobson and Brooke Grundfest Schoepf. New York: Basic Books.

-Luhmann, Niklas. 1995. Social Systems, translated by John Bednarz, Jr., with Dirk Baecker. Stanford, Calif.: Stanford University Press.

-Macy, Michael W. 1991. "Chains of Cooperation: Threshold Effects in Collective Action.” American Sociological Review 56:730-47.

-Mann, Michael. 1986. The Sources of Social Power. Vol. 1, A History of Powerfrom the Beginning to A.D. 1760. Cambridge: Cambridge University Press.

-Marx, Karl. 1977. Capital, vol. 1. Translated by Ben Fowkes. New York: Vintage Books. 1978. The Marx-Engels Reader, $2 d$ ed. Edited by Robert C. Tucker. New York: Norton.

-Mead, George Herbert. 1934. "Fragments on Ethics." Pp. 379-89 in Mind, Self, and Society: From the Standpoint of a Social Behaviorist, edited by Charles W. Morris. Chicago: University of Chicago Press. 
1964. “The Social Self." Pp. 142-49 in George Herbert Mead: Selected

Writings, edited by Andrew J. Reck. Indianapolis: Bobbs-Merrill.

-Melucci, Alberto. 1996. Challenging Codes: Collective Action in the Information Age. Cambridge: Cambridge University Press.

-Mischel, Walter. 1990. "Personality Dispositions Revisited and Revised: A View after Three Decades." Pp. 111-34 in Handbook of Personality: Theory and Research, edited by L. A. Pervin. New York: Guilford Press.

-Mischel, Walter, and Yuichi Shoda. 1995. "A Cognitive-Affective System Theory of Personality: Reconceptualizing Situations, Dispositions, Dynamics, and Invariance in Personality Structure." Psychological Review 102:246-68.

-Mitchell, Stephen A. 1988. Relational Concepts in Psychoanalysis: An Integration. Cambridge, Mass.: Harvard University Press.

-Mohr, John. 1994. "Soldiers, Mothers, Tramps, and Others: Discourse Roles in the 1907 New York City Charity Directory." Poetics 22:327-57.

-Ollman, Bertell. 1971. Alienation: Marx's Conception of Man in Capitalist Society. Cambridge: Cambridge University Press.

-Padgett, John F., and Christopher K. Ansell. 1993. "Robust Action and the Rise of the Medici, 1400-1434.” American Journal of Sociology 98:1259-1319.

-Parsons, Talcott. 1937. The Structure of Social Action: A Study in Social Theory with Special Reference to a Group of Recent European Writers. New York: Free Press.

1969. Politics and Social Structure. New York: Free Press.

-Parsons, Talcott, with Robert F. Bales and Edward A. Shils. 1953. Working Papers in the Theory of Action. New York: Free Press.

-Peirce, Charles Sanders. 1931-58. The Collected Papers of Charles Sanders Peirce, vol. 2. Edited by C. Hartshorne and P. Weiss. Cambridge, Mass.: Harvard University Press. 
-Pizzorno, Alessandro. 1991. "On the Individualistic Theory of Social Order." Pp. 209- 31 in Social Theory for a Changing Society, edited by Pierre Bourdieu and James S. Coleman. Boulder, Colo.: Westview; New York: Russell Sage Foundation.

-Ritzer, George, and Pamela Gindoff. 1992. "Methodological Relationism: Lessons for and from Social Psychology." Social Psychology Quarterly 55:12840.

-Rochberg-Halton, Eugene. 1986. Meaning and Modernity: Social Theory in the Pragmatic Attitude. Chicago: University of Chicago Press.

-Rorty, Richard. 1982. Consequences of Pragmatism: Essays, 1972-1980. Minneapolis: University of Minnesota Press.

-Saussure, Ferdinand de. 1959. Course in General Linguistics, edited by Charles Bally and Albert Sechehaye, in collaboration with Albert Riedlinger. Translated by Wade Baskin. New York: McGraw-Hill.

-Schafer, Roy. 1976. A New Language for Psychoanalysis. New Haven, Conn.: Yale University Press.

-Scott, Joan Wallach. 1988. Gender and the Politics of History. New York: Columbia University Press.

-Scott, John. 1991. Social Network Analysis: A Handbook. London: Sage.

-Sedgwick, Eve Kosofsky. 1990. Epistemology of the Closet. Berkeley and Los Angeles: University of California Press.

-Silverstein, Michael. 1979. "Language Structure and Linguistic Ideology." Pp. 193- 247 in The Elements: A Parasession on Linguistic Units and Levels, edited by Paul R. Clyne, William F. Hanks, and Carol L. Hofbauer. Chicago: Chicago Linguistic Society.

-Simmel, Georg. 1950. The Sociology of Georg Simmel, edited and translated by Kurt H. Wolff. New York: Free Press. 
. 1971. On Individuality and Social Forms, edited by Donald N. Levine. Chicago: University of Chicago Press.

. 1990. The Philosophy of Money, 2d ed. Edited by David Frisby, translated by Tom Bottomore and David Frisby, from a first draft by Kaethe Mengelberg. London: Routledge.

-Somers, Margaret R. 1993. "Citizenship and the Place of the Public Sphere: Law, Community, and Political Culture in the Transition to Democracy." American Sociological Review 58587-620.

. 1994. "Rights, Relationality, and Membership: Rethinking the Making and Meaning of Citizenship." Law and Social Inquiry 19:63-112.

1995. "What's Political or Cultural about Political Culture and the Public Sphere? Toward an Historical Sociology of Concept Formation." Sociological Theory 13:113-44.

-Somers, Margaret R., and Gloria D. Gibson. 1994. "Reclaiming the Epistemological 'Other': Narrative and the Social Constitution of Identity." Pp. 37-99 in Social Theory and the Politics of Identity, edited by Craig Calhoun. Oxford: Blackwell.

-Steinberg, Marc W. 1996. "Toward a Dialogic Analysis of Social Movement Culture: Reframing Frame Analysis." Paper presented at the meeting of the Social Science History Association, New Orleans.

-Stinchcombe, Arthur L. 1991. "The Conditions of Fruitfulness of Theorizing about Mechanisms in Social Science." Philosophy of the Social Sciences 21:36788 .

1995. Sugar Island Slavery in the Age of Enlightenment: The Political Economy of the Caribbean World. Princeton, N.J.: Princeton University Press.

-Thomas, William I., and Dorothy Swaine Thomas. 1928. The Child in America: BehaviorProblems and Programs. New York: Knopf.

-Tilly, Charles. 1978. From Mobilization to Revolution. Reading, Mass.: AddisonWesley. 
1993. "Mechanisms of State Formation and Collective Action." Interview by Ruud Koopmans and Sophie de Schaepdrijver. CSSC Working Papers Series no.171. New School for Social Research.

1995a. "To Explain Political Processes." American Journal of Sociology 101:1594-1610.

. 1995b. "Durable Inequality." CSSC Working Papers Series no. 224. New School for Social Research.

-Waugh, Linda R., and Monique Monville-Burston. 1990. "Introduction: The Life, Work, and Influence of Roman Jakobson." Pp. 1-45 in Roman Jakobson: On Language. Cambridge, Mass.: Harvard University Press.

-Wellman, Barry. 1988. "Structural Analysis: From Method and Metaphor to Theory and Substance." Pp. 19-61 in Social Structures: A Network Approach, edited by Barry Wellman and S. D. Berkowitz. Cambridge: Cambridge University Press.

-White, Harrison C. 1966. "Notes on the Constituents of Social Structure." Manuscript. Harvard University, Department of Sociology.

. 1973. "Everyday Life in Stochastic Networks." Sociological Inquiry 43:43- 49 .

. 1992. Identity and Control: A Structural Theory of Social Action. Princeton, N.J.: Princeton University Press.

. 1994a. "Network Switches, Domination, and Grammars: Is It Soul or Ties that Engender Language?” Manuscript. Columbia University, Department of Sociology.

. 1994b. "Social Networks Can Resolve Actor Paradoxes in Economics and in Psychology.” Pre-Print Series, Columbia University, Center for the Social Sciences.

1996. "Network Switchings and Bayesian Forks: Reconstructing the Social and Behavioral Sciences." Social Research 62:1035-63. 
. 1997. "Can Mathematics Be Social? Flexible Representations for Interaction Process and Its Sociocultural Constructions." Sociological Forum 12:53-71.

-White, Harrison C., Scott A. Boorman, and Ronald L. Breiger. 1976. "Social Structure from Multiple Networks: I. Blockmodels of Roles and Positions." American Journal of Sociology 81930-80.

-Wiley, Norbert. 1994. The Semiotic Self: Chicago: University of Chicago Press.

-Wright, Erik Olin. 1979. Class Structure and Income Determination. New York: Academic Press.

-Zerubavel, Eviatar. 1991. The Fine Line. New York: Free Press. 
